\title{
Identification of new cancer stem cell markers and signaling pathways in HER-2-positive breast cancer by transcriptome sequencing
}

\author{
LU FENG $^{1 *}$, SHANGKE HUANG $^{2 *}$, GAILI AN $^{3}$, GUANYING WANG $^{1}$, SHANZHI GU ${ }^{*}$ and XINHAN ZHAO ${ }^{*}$ \\ ${ }^{1}$ Department of Medical Oncology, The First Affiliated Hospital of Xi'an Jiaotong University, Xi'an, \\ Shaanxi 710061; ${ }^{2}$ Department of Oncology, The Affiliated Hospital of Southwest Medical University, Luzhou, \\ Sichuan 646000; ${ }^{3}$ Department of Clinical Oncology, Shaanxi Provincial People's Hospital, Xi'an, Shaanxi 710068; \\ ${ }^{4}$ College of Forensic Medicine, Xi'an Jiaotong University Health Science Center, Xi'an, Shaanxi 710061, P.R. China
}

Received December 11, 2018; Accepted June 6, 2019

DOI: $10.3892 /$ ijo.2019.4876

\begin{abstract}
Human epidermal growth factor receptor (HER)-2-positive breast cancer accounts for $\sim 25 \%$ of all breast cancer cases, has a high propensity for relapse, metastasis and drug resistance, and is associated with a poor prognosis. Therefore, it is necessary to develop more effective therapeutic targets for the treatment of HER-2-positive breast cancer. CD $44^{+} / \mathrm{CD} 24^{-/ \text {low }}$ is currently the most commonly used marker for breast cancer stem cells (CSCs), which are considered the main cause of drug resistance, relapse and metastasis. In the present study, the ratio of $\mathrm{CD} 44^{+} / \mathrm{CD} 24^{-/ \text {low }}$ cells was almost zero in SK-BR-3 cells; however, it was $>90 \%$ in MDA-MB-231 cells, as determined by flow cytometry. Since SK-BR-3 and MDA-MB-231 cells both exhibit a strong propensity for invasion and migration, it was hypothesized that there may be other markers of CSCs in SK-BR-3 cells. Therefore, transcriptome sequencing was performed for SK-BR-3 and MDA-MB-231 cells. It was observed that several leukocyte differentiation antigens and other CSC markers were significantly more highly expressed in SK-BR-3 cells. Furthermore, the expression of aldehyde dehydrogenase (ALDH)1A3, CD164 and epithelial cell adhesion molecule (EpCAM) was higher in
\end{abstract}

Correspondence to: Professor Shanzhi Gu, College of Forensic Medicine, Xi'an Jiaotong University Health Science Center, 277 Yanta Western Road, Xi'an, Shaanxi 710061, P.R. China

E-mail: gushanzhi@mail.xjtu.edu.cn

Professor Xinhan Zhao, Department of Oncology, The First Affiliated Hospital of Xi'an Jiaotong University, 277 Yanta Western Road, Xi'an, Shaanxi 710061, P.R. China

E-mail: zhaoxinhanprof@163.com

*Contributed equally

Key words: cancer stem cell markers, signaling pathways, transcriptome sequencing, human epidermal growth factor receptor-2-positive breast cancer
SK-BR-3 cells compared with in other subtypes of breast cell lines, as determined by reverse transcription-polymerase chain reaction and western blot analysis. In addition, the expression levels of ALDH1A3, ALDH3B2 and EpCAM were higher in HER-2-positive breast cancer compared with in paracancerous tissues and other subtypes of breast cancer, as determined by immunohistochemistry. The expression of $\beta$-catenin in the Wnt signaling pathway was lower in SK-BR-3 cells compared with in MDA-MB-231 cells, which may be used as a prognostic indicator for breast cancer. These findings may help identify novel CSC markers and therapeutic targets for HER-2-positive breast cancer.

\section{Introduction}

Breast cancer is a highly prevalent malignancy in women; however, its exact etiology and the mechanisms underlying breast carcinogenesis remain elusive. Notably, the incidence of breast cancer is increasing annually, and it is a highly heterogeneous disease at the molecular level $(1,2)$. Perou et al (3) analyzed the gene expression patterns of 65 breast cancer specimens using a cDNA microarray that contained 8,102 genes, and 65 specimens of breast cancer were divided into five subtypes on the basis of further screening as follows: Luminal A, luminal B, human epidermal growth factor receptor (HER)-2-overexpressing, triple-negative breast cancer (TNBC) and normal-like breast cancer. Furthermore, $20-25 \%$ of patients with breast cancer have HER-2 gene mutations and exhibit HER-2 overexpression, which is a characteristic closely associated with resistance to treatment and poor prognosis $(4,5)$.

Trastuzumab (Herceptin ${ }^{\circledR}$; Genentech, Inc.), the first humanized monoclonal antibody (immunoglobulin G1), binds directly to the extracellular domain of the HER-2 protein and has been proven to be beneficial for patients with HER-2-positive early-stage breast cancer, as well as metastatic breast cancer (6-8). Compared with chemotherapy alone, trastuzumab combined with chemotherapy can prolong time-to-tumor progression, increase objective response rate and prolong overall survival (9). However, a number of 
HER-2-positive patients do not benefit from trastuzumab, due to drug resistance (10). In addition, patients with HER-2-positive breast cancer have higher metastasis and recurrence rates, and a shorter survival time (11). Therefore, it is necessary to develop more effective medicines and identify novel therapeutic targets for the treatment of HER-2-positive breast cancer.

TNBC has the worst prognosis among all types of breast cancer (12). Due to its refractoriness to current clinical estrogen and targeted therapies, it has a high rate of distant metastasis, recurrence and mortality $(13,14)$. To investigate the poorer prognosis of TNBC and HER-2-positive breast cancer, this study compared the invasion and migration of SK-BR-3 and MDA-MB-231 cells, and observed the difference in the ratio of $\mathrm{CD} 44^{+} / \mathrm{CD} 24^{- \text {llow }}$ cells between SK-BR-3 and MDA-MB-231 cells. The results demonstrated that the invasiveness and migration of SK-BR-3 and MDA-MB-231 cells were prominent; however, the $\mathrm{CD} 44^{+} / \mathrm{CD} 24^{-/ \text {low }}$ ratio was almost 0 in SK-BR-3 cells, whereas the proportion of CD $44^{+} / \mathrm{CD} 24^{-/ \text {low }}$ cells was $>90 \%$ among MDA-MB-231 cells. Based on these results, it was hypothesized that there may be other cancer stem cells (CSCs) markers in SK-BR-3 cells. The transcriptome links the genetic information of the genome with the biological function of the proteome, and it also forms the basis and starting point for the study of gene function and structure $(15,16)$. In the present study, SK-BR-3 and MDA-MB-231 cells were sequenced and analyzed in order to identify novel CSC markers and design new therapeutic strategies for the treatment of HER-2-positive breast cancer.

\section{Materials and methods}

Cell culture. The human normal breast cell line MCF-10A, and human breast cancer cell lines MCF-7 and MDA-MB-231 were purchased from the Shanghai Cell Bank, Chinese Academy of Sciences. The human breast cancer cell line SK-BR-3 was obtained from the Kunming Cell Bank, Chinese Academy of Sciences. MCF-10A cells were cultured in DMEM/F12 supplemented with $5 \%$ horse serum, $10 \mu \mathrm{g} / \mathrm{ml}$ insulin, $20 \mathrm{ng} / \mathrm{ml}$ epidermal growth factor, $100 \mathrm{ng} / \mathrm{ml}$ cholera toxin and $0.5 \mu \mathrm{g} / \mathrm{ml}$ hydrocortisone (all Sigma-Aldrich; Merck KGaA). The other breast cancer cell lines were cultured in DMEM or RPMI-1640 McCoy's 5A medium (HyClone; GE Healthcare Life Sciences) supplemented with $10 \%$ fetal bovine serum (FBS; Gibco, Thermo Fisher Scientific, Inc.), $1 \%$ penicillin and streptomycin at $37^{\circ} \mathrm{C}$ in an incubator containing $5 \% \mathrm{CO}_{2}$.

Flow cytometry. Cells were collected by trypsinization, centrifuged at $800 \mathrm{x}$ g for $5 \mathrm{~min}$ and washed twice with phosphate-buffered saline (PBS). Subsequently, $5 \times 10^{5}$ cells were resuspended in $100 \mu \mathrm{l}$ PBS containing $5 \mu \mathrm{l}$ CD44-PE (cat. no. ab46793; 1:20; Abcam) and CD24-FITC antibodies (cat.no. ab30350; 1:20; Abcam) at $4^{\circ} \mathrm{C}$ for $30 \mathrm{~min}$. After the cells were washed with PBS, PBS was added to the cells to obtain a total volume $500 \mu \mathrm{l}$, and the stained cells were performed by BD FACS Canto flow cytometry (BD Biosciences). The data were analyzed using FlowJo (Tree Star, Inc.).

Cell migration and invasion assays. For the cell migration assays, a $8-\mu \mathrm{m}$ pore Transwell chamber (EMD Millipore) was inserted into 24 -well plates. A total of $600 \mu \mathrm{l}$ complete medium supplemented with $10 \%$ FBS was added to the lower chamber. A total of $2 \times 10^{4}$ cells/well suspended in $200 \mu \mathrm{l}$ complete FBS-free medium (DMEM or RPMI-1640) were seeded into the upper chamber. After cells were cultured for $24 \mathrm{~h}$, the non-migrated cells were removed from the top surface of the membrane using a cotton swab. The migrated cells that adhered to the permeable membrane were fixed with $4 \%$ formalin at room temperature for $30 \mathrm{~min}$ and stained with $0.1 \%$ crystal violet solution at room temperature for $15-20 \mathrm{~min}$. The cells were then observed under an inverted light microscope and were counted in 10 random fields of view. The cell invasion assay was conducted in a similar manner to the migration assay, with the exception that the membrane was coated with Matrigel (BD Bioscience) and the cells were cultured for $24 \mathrm{~h}$.

Serum-free suspension culture of breast cancer cell lines. The SK-BR-3 and MDA-MB-231 cells were incubated in RPMI-1640 McCoy's 5A medium (including 2\% B27, $20 \mathrm{ng} / \mathrm{ml}$ epidermal growth factor and $10 \mathrm{ng} / \mathrm{ml}$ fibroblast growth factor; Sigma-Aldrich; Merck KGaA) without serum suspension, and were incubated at $37^{\circ} \mathrm{C}$ in an atmosphere containing $5 \% \mathrm{CO}_{2}$. The culture was gently oscillated twice a day and the medium was changed every 3 days, followed by gentle centrifugation $(200 \mathrm{x} \mathrm{g}, 5 \mathrm{~min})$ and collection of the microspheres. The microspheres were observed under an inverted light microscope.

Transcriptome sequencing. Total RNA was extracted from the cells using fast2000 kit (Fast Agen) and RNA was treated with DNase I (1U/ $\mu 1$, Thermo Fisher Scientific, USA). Magnetic beads with Oligo (dT) were used to enrich mRNA. Fragmentation buffer was used to obtain short fragments of mRNA (17). cDNA was then synthesized using the mRNA fragments as templates with the Agencourt AMPure XP Kit (Beckman Coulter, Inc.), according to the manufacturer's protocol. Short fragments were purified and recycled with EB buffer for end reparation and base 'A' addition (17). Subsequently, the 200-500 bp size of the fragments was selected for polymerase chain reaction (PCR) amplification as follows: $98^{\circ} \mathrm{C}$ for $30 \mathrm{sec}$, one cycle; $98^{\circ} \mathrm{C}$ for $10 \mathrm{sec}, 15$ cycles; $60^{\circ} \mathrm{C}$ for $30 \mathrm{sec}, 72^{\circ} \mathrm{C}$ for $30 \mathrm{sec}$ and last cycle at $72^{\circ} \mathrm{C}$ for $5 \mathrm{~min}$. During the quality control (QC) steps, the constructed library was qualified and quantified by Agilent 2100 Bioanalyzer (Agilent Technologies, Inc.) and ABI StepOnePlus Real-Time PCR system (Applied Biosystems; Thermo Fisher Scientific, Inc.) quality inspection. Finally, Illumina HiSeq ${ }^{\mathrm{TM}} 2000$ (Illumina, Inc.) was used for sequencing (Beijing Genomics Institute).

Bioinformatics analysis. Primary sequencing data obtained from Illumina $\mathrm{HiSeq}^{\mathrm{TM}} 2000$ sequencing were referred to as raw reads. After filtering, clean reads were obtained and were used for downstream bioinformatics analysis. We performed quality control (QC) on clean data through drawing a base composition chart and quality distribution chart. After passing QC, cleans reads were aligned to the human genome (hg19) using BWA software (18), gene expression levels were quantified by a software package: RSEM (RNASeq by Expectation Maximization) (17). The differentially expressed genes (DEGs) between SK-BR-3 and MDA-MB-231 cells were screened using the Poisson distribution (19). In addition, Gene Ontology (GO) enrichment analysis involved the mapping of all DEGs 
Table I. Primer sequences for reverse transcription-quantitative polymerase chain reaction.

\begin{tabular}{lll}
\hline Gene & \multicolumn{1}{c}{ Forward primer $\left(5^{\prime}-3^{\prime}\right)$} & \multicolumn{1}{c}{ Reverse primer $\left(5^{\prime}-3^{\prime}\right)$} \\
\hline ALDH1A3 & AATCCAGGGCAAGACCATC & TTCCACACCAGCATCAGC \\
CD24 & TGCTGGCACTGCTCCTACC & CGAAGAGACTGGCTGTTGACTG \\
CD44 & GCAGGAAGAAGGATGGATATGG & TCAGAGTAGAAGTTGTTGGATGG \\
CD109 & TGTCTCCTTCCCACATCCTC & CAGCTTCTTTCCCAAACTGC \\
CD164 & AACAGTTAGTGATTGTCAAGTGG & CAGGTTGTGAGGTTGGAGTC \\
EPCAM & GCTGGTGTGAACACTGCT & ACGCGTTGTGACTCCTTCT \\
GAPDH & AAGGCTGTGGGCAAGGTCATC & GCGTCAAAGGTGGAGGAGTGG
\end{tabular}

ALDH1A3, aldehyde dehydrogenase 1 family member A3; EpCAM, epithelial cell adhesion molecule.

to GO terms in the database (http://www.geneontology.org/), calculating gene numbers for every term. Then, the hypergeometric test was employed to identify significantly enriched GO terms in the input list of DEGs (20). Kyoto Encyclopedia of Genes and Genomes (KEGG) was used to perform pathway enrichment analysis of DEGs, and we could to see detailed pathway information in KEGG database (21).

Reverse transcription-quantitative PCR (RT-qPCR) analysis. Total RNA was extracted from cultured cells using TRIzol ${ }^{\circledR}$ reagent (Invitrogen; Thermo Fisher Scientific, Inc.), according to the manufacturer's protocol. Subsequently, $1 \mu \mathrm{g}$ total RNA was used to synthesize cDNA with the PrimeScript Reverse Transcriptase Reagent kit (Takara Bio, Inc.), according to manufacturer's protocol. RT-qPCR was performed using the SYBR Green PCR kit (Takara Bio, Inc.) in $94^{\circ} \mathrm{C}$ denatured for $3 \mathrm{~min}$, one cycle; then 35 cycles: $94^{\circ} \mathrm{C}$ denatured for $30 \mathrm{sec}, 58^{\circ} \mathrm{C}$ annealed for $30 \mathrm{sec}, 72^{\circ} \mathrm{C}$ prolonged for $45 \mathrm{sec}$, and finally prolonged for $10 \mathrm{~min}$ at $72^{\circ} \mathrm{C}$. Using GAPDH as an internal control, the relative mRNA expression levels were assessed using the $2^{-\Delta \Delta \mathrm{Cq}}$ method (22). The primer sequences are listed in Table I.

Gene and isoform expression. Gene and isoform expression levels were quantified using the RNASeq by Expectation Maximization (RSEM) software package (17). RSEM computes maximum likelihood abundance estimates using the Expectation-Maximization algorithm for its statistical model, including the modeling of paired-end and variable-length reads, fragment length distributions and quality scores, to determine which transcripts are isoforms of the same gene. The Fragments Per Kilobase of transcript per Million (FPKM) method was used to calculate expression level, as follows: FPKM $=\left(10^{6} \mathrm{C}\right) /\left(\mathrm{NL} / 10^{3}\right)$; for gene $\mathrm{A}, \mathrm{C}$ is the number of fragments that are uniquely aligned to gene $\mathrm{A}, \mathrm{N}$ is the total number of fragments that were uniquely aligned to all genes, and $\mathrm{L}$ is the number of bases on gene A. FPKM values were obtained in SK-BR-3 and MDA-MB-231 cells. Log $_{2}$ Ratio=SK-BR-3-FPKM/MDA-MB-231-FPKM.

Western blot analysis. Cells were placed on ice and washed twice with PBS. A total of $200 \mu 1$ RIPA buffer (Cell Signaling Technology, Inc.) containing protease inhibitors was added and mixed well. After $30 \mathrm{~min}$ of cells lysis on ice, the cells were collected from the culture dish; all liquids were transferred to the new centrifuge tube and centrifuged at $4^{\circ} \mathrm{C}$ and $14,000 \mathrm{x} \mathrm{g}$ for $10 \mathrm{~min}$. The supernatant was carefully transferred to the $1.5 \mathrm{ml} \mathrm{EP}$ tube as required protein. Protein concentration was determined using the bicinchoninic acid protein assay (Sigma-Aldrich; Merck KGaA). Denatured proteins $(50 \mu \mathrm{g})$ were separated by 5-10\% SDS-PAGE and transferred to PVDF membranes (EMD Millipore). The membranes were blocked with $5 \%$ non-fat milk in PBS-0.1\% Tween (PBST) at room temperature for $1-2 \mathrm{~h}$ and were incubated with primary antibodies at $4^{\circ} \mathrm{C}$ overnight. After washing with PBST, the membranes were incubated with secondary horseradish peroxidase-conjugated goat anti-rabbit (cat. no. ab205718; 1:2,000; Abcam)/goat anti-mouse antibodies (cat. no. ab6789; 1:2,000; Abcam) for 1-2 $\mathrm{h}$ at room temperature. The primary antibodies used were anti-aldehyde dehydrogenase (ALDH)1A1 (rabbit monoclonal; cat. no. ab52492; 1:50; Abcam), anti-ALDH1A3 (rabbit polyclonal; cat. no. ab129815; 1:200; Abcam), anti-CD24 (rabbit monoclonal; cat. no. ab179821; 1:1,000; Abcam), anti-CD44 (rabbit monoclonal; cat. no. ab51037; 1:2,000; Abcam), anti-CD109 (rabbit polyclonal; cat. no. ab128470; 1:500; Abcam), anti-CD164 (rabbit polyclonal; cat. no.PA5-80418; 1:500; Invitrogen; Thermo Fisher Scientific, Inc.), anti-epithelial cell adhesion molecule (EpCAM; rabbit monoclonal; cat. no. ab223582; 1:1,000; Abcam) and anti- $\beta$-actin (mouse monoclonal; cat. no. sc-47778; 1:2,000; Santa Cruz Biotechnology, Inc.). After washing with PBST, chemiluminescent liquid (SuperSignal ${ }^{\mathrm{TM}}$ West Pico PLUS Chemiluminescent Substrate, Thermo Fisher Scientific, Inc.) was applied for $\sim 5 \mathrm{~min}$ at room temperature in the dark prior to visualizing membranes. Protein band images were acquired by ChemiDoc MP Imaging System (Bio-Rad Laboratories, Inc.).

Patients. A total of 109 breast cancer cases were randomly selected from the Department of Pathology, The First Affiliated Hospital of Xi'an Jiaotong University, between January 2014 and December 2016. The common clinicopathological characteristics and the expression of estrogen receptor (ER), progesterone receptor (PR), HER-2, Ki-67 and molecular markers (EpCAM, ALDH1A3 and ALDH3B2) were analyzed. According to the expression of ER, PR, HER-2 and Ki-67, breast cancer was divided into four subtypes as follows: Luminal A, luminal B, HER-2-positive and TNBC. 
Immunohistochemistry. Immunohistochemistry was performed on $4-\mu \mathrm{m} 4 \%$ formalin-fixed overnight at $4^{\circ} \mathrm{C}$, paraffin-embedded breast cancer and paracancerous tissue sections. The sections conventional dimethylbenzene dewaxing, gradient alcohol dehydration: Dimethylbenzene I 5 min, dimethylbenzene II $5 \mathrm{~min}, 100 \%$ alcohol I $5 \mathrm{~min}, 95 \%$ alcohol I $5 \mathrm{~min}, 95 \%$ alcohol II 5 min. Blocking of endogenous peroxidase activity: The sections were placed in $0.3 \%$ hydrogen peroxide water prepared with methanol at room temperature for 15 min, washed PBS for 5 min three times. Antigen retrieval: The sections were boiled $\left(95^{\circ} \mathrm{C}, 15 \sim 20 \mathrm{~min}\right)$ in $0.01 \mathrm{~mol} / 1 \mathrm{citric}$ acid buffer $(\mathrm{PH}=6.0)$, cooled naturally for more than $20 \mathrm{~min}$, then washed with cold water to accelerate cooling to room temperature, washed PBS for 5 min three times. The slides were then incubated with anti-EpCAM (rabbit monoclonal; cat. no. ab223582; 1:500; Abcam), anti-ALDH1A3 (rabbit polyclonal; cat. no. ab129815; 1:100; Abcam) and anti-ALDH3B2 (rabbit polyclonal; cat. no. ab238866; 1:20; Abcam) overnight at $4^{\circ} \mathrm{C}$. The primary antibody was omitted in the negative control experiment. After washing with PBS for 5 min three times, the sections were incubated with biotinylated goat anti-rabbit IgG (cat. no. ab64256; 1:400; Abcam) at $37^{\circ} \mathrm{C}$ for $30 \mathrm{~min}$. Next, the sections were dropped with streptavidin-horseradish peroxidase (cat. no. 21126; $5 \mu \mathrm{g} / \mathrm{ml}$; Thermo Fisher Scientific, Inc.) at $37^{\circ} \mathrm{C}$ for $30 \mathrm{~min}$, washed PBS for $5 \mathrm{~min}$ three times. Color was developed using diaminobenzidine (DAB) substrate kit (cat. no. 34065; Thermo Fisher Scientific, Inc.) avoiding light.

Five non-overlapping visual fields were randomly selected under a light microscope at a magnification of x200, and the percentage of positively stained cells and staining intensity were comprehensively analyzed. ALDH1A3 and ALDH3B2 were located in the cytoplasm, whereas positive staining for EpCAM was located in the cell membrane. The percentage of ALDH1A3- and ALDH3B2-positive cells was calculated in tumor tissues; $>10 \%$ positive cells was considered as positive staining and $<10 \%$ positive was considered as a negative result.

EpCAM staining was mainly located in the cytoplasm and cell membrane, and only partially expressed in the nucleus. According to the number of EpCAM-positive cells among cancer cells, the scores were defined as follows: 0, 10\%; $1,10-30 \% ; 2,30-50 \% ; 3,50-70 \%$; and $4,70 \%$. In addition, the positive staining intensity score ( $0-3$ points) was defined as follows: 0 points, none; 1 point, weak; 2 points, medium; and 3 points, strong staining. The collective score was up to 7 points. A score of $\geq 4$ points was considered as positive.

Statistical analysis. GraphPad Prism 6 (GraphPad Software, Inc.) was used for statistical analysis. Student's t-test was used to analyze the differences in invasion and migration between SK-BR-3 and MDA-MB-231 cells. Comparison of variables among different breast cancer cell lines was performed by one-way analysis of variance followed by the post hoc Tukey's multiple comparison test. $\mathrm{P}<0.05$ was considered to indicate a statistically significant difference.

\section{Results}

Characteristics of CD $44^{+} / C D 24^{-/ l o w}$ SK-BR-3 and MDA-MB-23 cells. Since CD $44^{+} / \mathrm{CD} 24^{-/ \text {low }}$ is currently the most commonly used marker for breast CSCs (23), the protein expression levels of CD44 and CD24 were detected in different breast cancer cell subtypes by flow cytometry. The results revealed that there were almost no CD44+/CD24-/low cells among SK-BR-3 and $\mathrm{MCF}-7$ cells. However, the ratio of $\mathrm{CD} 44^{+} / \mathrm{CD} 24^{-/ \text {low }}$ cells was $>90 \%$ in MDA-MB-231 cells $(\mathrm{P}<0.001$; Fig. $1 \mathrm{~A})$. In addition, it has been reported that $\mathrm{CD} 44^{+} / \mathrm{CD} 24^{-/ \text {low }}$ cells exhibit stronger invasion, metastasis and tumor-forming abilities $(23,24)$. Therefore, migratory and invasive abilities were compared between SK-BR-3 and MDA-MB-231 cells using Transwell assays. The results demonstrated that both SK-BR-3 and MDA-MB-231 cells exhibited strong migratory and invasive abilities ( $\mathrm{P}>0.05$; Fig. 1B). The activity of breast CSCs, as manifested by microsphere formation (25), was higher in MDA-MB-231 cells compared with in SK-BR-3 cells (Fig. 1C). These results indicated that, although $\mathrm{CD} 44^{+} / \mathrm{CD} 24^{-/ \text {low }}$ breast cancer cells have the characteristics of CSCs, CD $44^{+} / \mathrm{CD} 24^{-/ \text {low }}$ may not be an accurate stem cell marker of SK-BR-3 cells. Therefore, there may be other CSC markers in SK-BR-3 cells that require further research.

Sequencing data of SK-BR-3 and MDA-MB-231 cells. Using the Illumina HiSeq ${ }^{\mathrm{TM}} 2000$ platform, SK-BR-3 and MDA-MB-231 cells were sequenced. However, as the original sequencing data may contain low-quality sequences, in order to ensure the reliability of the results, raw reads containing the adapter sequence, a high content of unknown bases and low-quality reads were removed (Fig. 2A). Clean reads were obtained after filtering and were used for downstream bioinformatics analysis. Subsequently, base composition and quality distribution charts of the clean reads were generated; obtained low-quality $(<20)$ base ratio was low, which indicated that the quality of the sequencing was relatively good (Fig. 2B and C). Sequence reads were aligned to the human genome using BWA software (18). Clean reads were mapped to the reference genome, and the statistics of alignment results yielded a mean coverage of $81.23 \%$ for SK-BR-3 and $81.54 \%$ for MDA-MB-231 cells. Furthermore, we identified that 16,616 genes were-expressed in SK-BR-3 cells and 16,783 genes were expressed in MDA-MB-231 cells

The differentially expressed genes (DEGs) between SK-BR-3 and MDA-MB-231 cells were then identified using the Poisson distribution (19). Subsequently, the multiple hypothesis test was adjusted for the P-value of differential gene expression and the P-value was determined by controlling the false discovery rate (FDR). FDR $\leq 0.001$ and an absolute value of $\log 2$ ratio $\geq 1$ were used as the cut-off points for assessing the significance of differences in gene expression. According to this cut-off, 6,305 genes were selected that were differentially expressed between SK-BR-3 and MDA-MB-231 cells at $\mathrm{P}<0.05$ corrected with FDR $\leq 0.001$.

Upregulation and downregulation of CSC markers in SK-BR-3 vs. MDA-MB-231 cells. CD44+/CD24-/low cells are usually considered to be CSCs in breast cancer (23). These cells have a higher invasive and metastatic potential (24), and are resistant to conventional chemotherapy and radiotherapy, which are the main reasons for recurrence and metastasis of breast cancer $(26,27)$. However, the present study revealed that there almost no CD44 expression was detected in SK-BR-3 cells. Therefore, novel CSC markers for SK-BR-3 cells are 
A
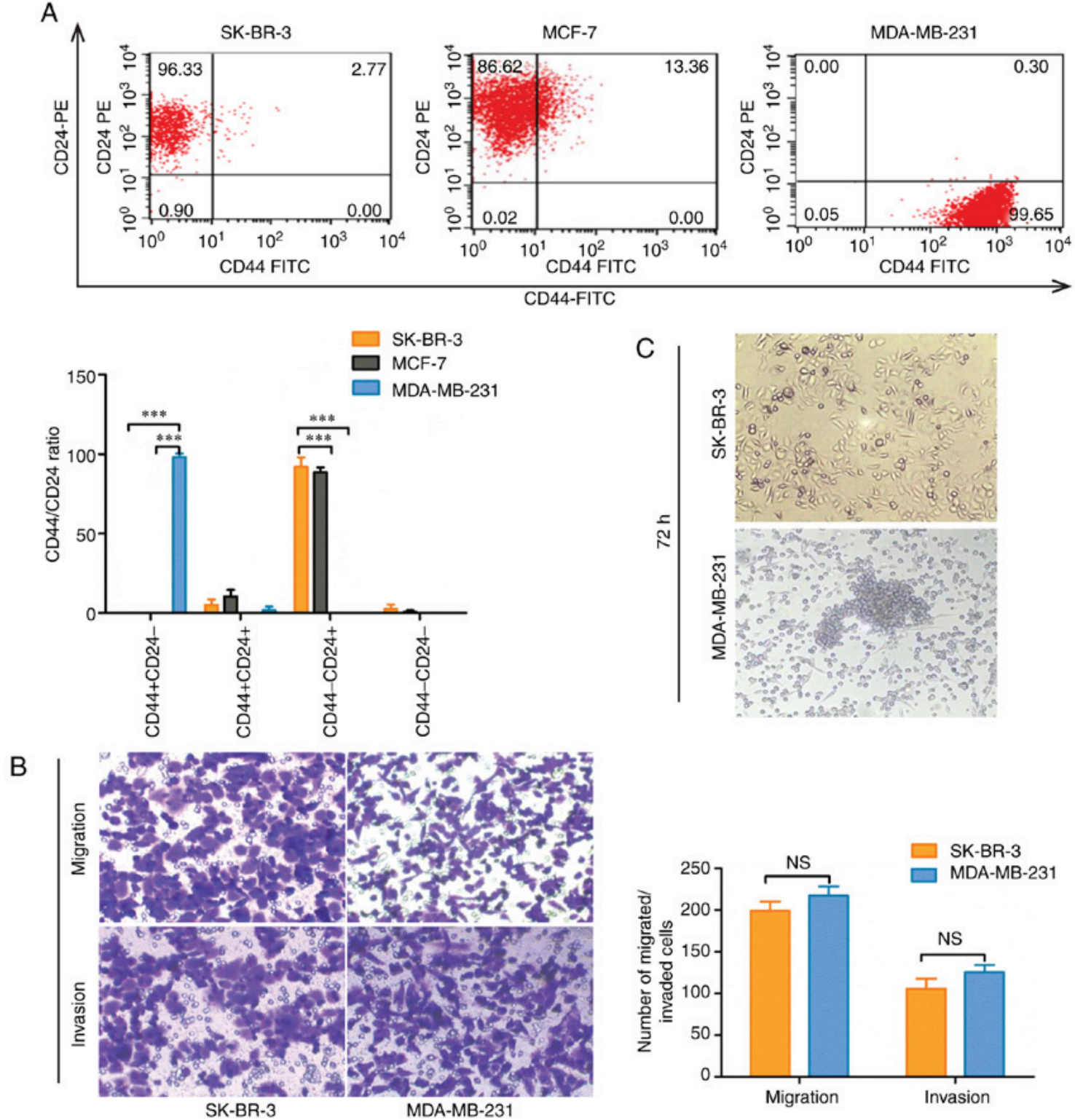

Figure 1. $\mathrm{CD} 44^{+} / \mathrm{CD} 24^{-/ / \mathrm{low}}$ expression, migration, invasion and microsphere formation were compared in different breast cancer cell subtypes. Three breast cancer cell lines were compared: SK-BR-3 (human epidermal growth factor receptor-2-overexpressing subtype), MCF-7 (luminal A subtype) and MDA-MB-231 (triple-negative breast cancer subtype). (A) Analysis of the CD44/CD24 ratio in SK-BR-3, MCF-7 and MDA-MB-231 cells by flow cytometry. Data were analyzed using one-way analysis of variance. ${ }^{* * *} \mathrm{P}<0.001$. (B) Transwell migration and invasion assays were performed in SK-BR-3 and MDA-MB-231 cells (magnification, x200). Data were analyzed using Student's t-test. (C) Serum-free suspension culture of SKBR-3 and MDA-MB-231 cells (magnification, x200). ns, not significant; PE, phycoerythrin.

required. As leukocyte differentiation antigens have been used as stem cell markers in a number of tumors (28), this study investigated the alterations in leukocyte differentiation antigens, among which CD24, CD109 and CD164 exhibited increased expression in SK-BR-3 cells (Fig. 3A; Table II). The expression of ALDH1A1, ALDH1A3 and ALDH3B2 was also significantly increased in SK-BR-3 cells (Fig. 3B; Table II). Furthermore, CSC markers, such as EpCAM, were markedly upregulated in SK-BR-3 cells. Conversely, other typical stem cell genes, including $\mathrm{C}-\mathrm{X}-\mathrm{C}$ motif chemokine receptor 4, CD44, protein $\mathrm{C}$ receptor and integrin subunit $\beta 1$, were downregulated (Fig. 3C; Table II). Furthermore, epithelial-to-mesenchymal transition (ETM)-related gene expression was examined in SK-BR-3 cells. Certain epithelial marker genes, including CD24, claudin (CLDN)3, CLDN8 and erb-b2 receptor tyrosine kinase 2 (ERBB2), were upregulated (Fig. 3D, Table II), whereas mesenchymal markers, such as actin $\alpha 2$, smooth muscle (ACTA2), cadherin 11 (CDH11), fibronectin 1 (FN1), integrin subunit $\alpha 5$ (ITGA5), snail family transcriptional repressor 2 (SNAI2) and vimentin (VIM), were markedly downregulated (Fig. 3E; Table II).

Analysis of expression levels in $S K-B R-3$ vs. MDA-MB-23I cells. The expression levels of ALDH1A3, ALDH3B2, CD24, CD164 and EpCAM were markedly higher in SK-BR-3 cells (Fig. 4A; Table II). Furthermore, the RT-qPCR data revealed that ALDH1A3, CD24, CD109, CD164 and EpCAM were more strongly expressed in SK-BR-3 cells compared with in MDA-MB-231 cells (Fig. 4B). Subsequently, the protein expression levels of ALDH1A1, ALDH1A3, CD24, CD44, 
A
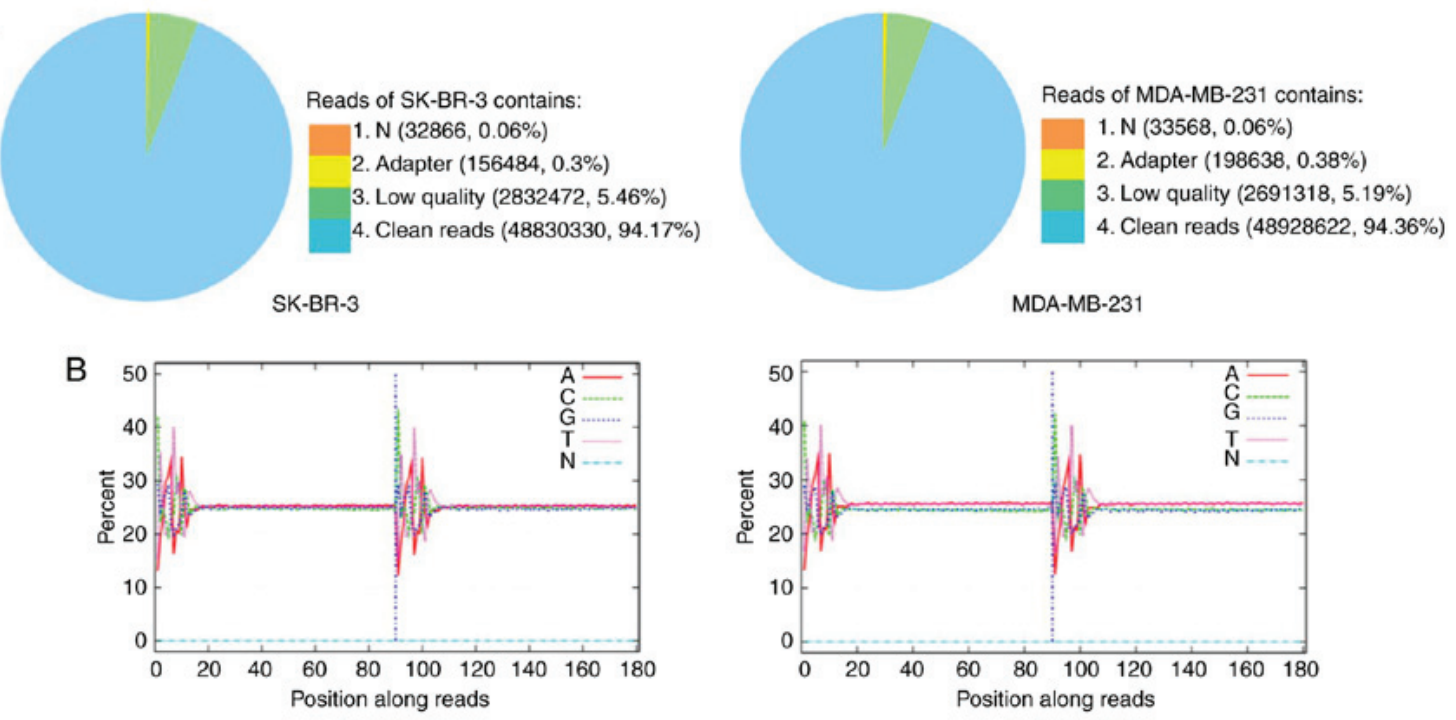

SK-BR-3

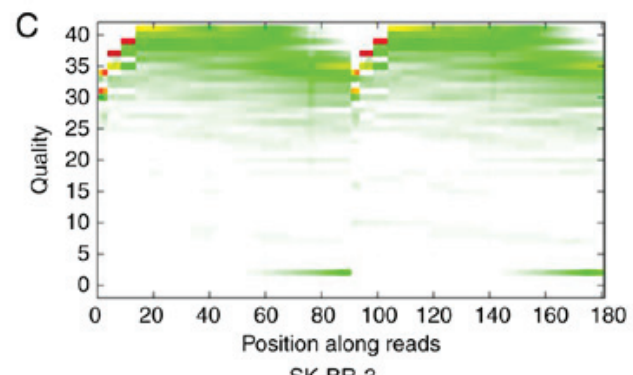

SK-BR-3

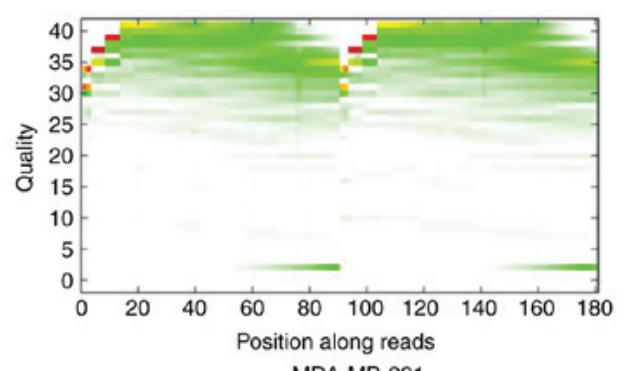

Figure 2. Sequencing data of SK-BR-3 and MDA-MB-231 cells. (A) Pie chart of raw reads component ratio of SK-BR-3 and MDA-MB-231 cells. (B) Base composition of clean reads. On the x axis, position 1-90 bp represents read 1, and 91-180 bp represents read 2 . The A curve should overlap with the T curve, while the G curve should overlap with the C curve. The SK-BR-3 and MDA-MB-231 clean reads exhibited a balanced composition. (C) Quality distribution of bases along reads. Horizontal axis, positions along reads; vertical axis, quality value. Each dot in the image represents the quality value of the corresponding position along reads; colors of the dots indicate base quality. If the percentage of the bases with low quality $(<20)$ is low, the sequencing quality of SK-BR-3 cells and MDA-MB-231 cells is considered satisfactory.
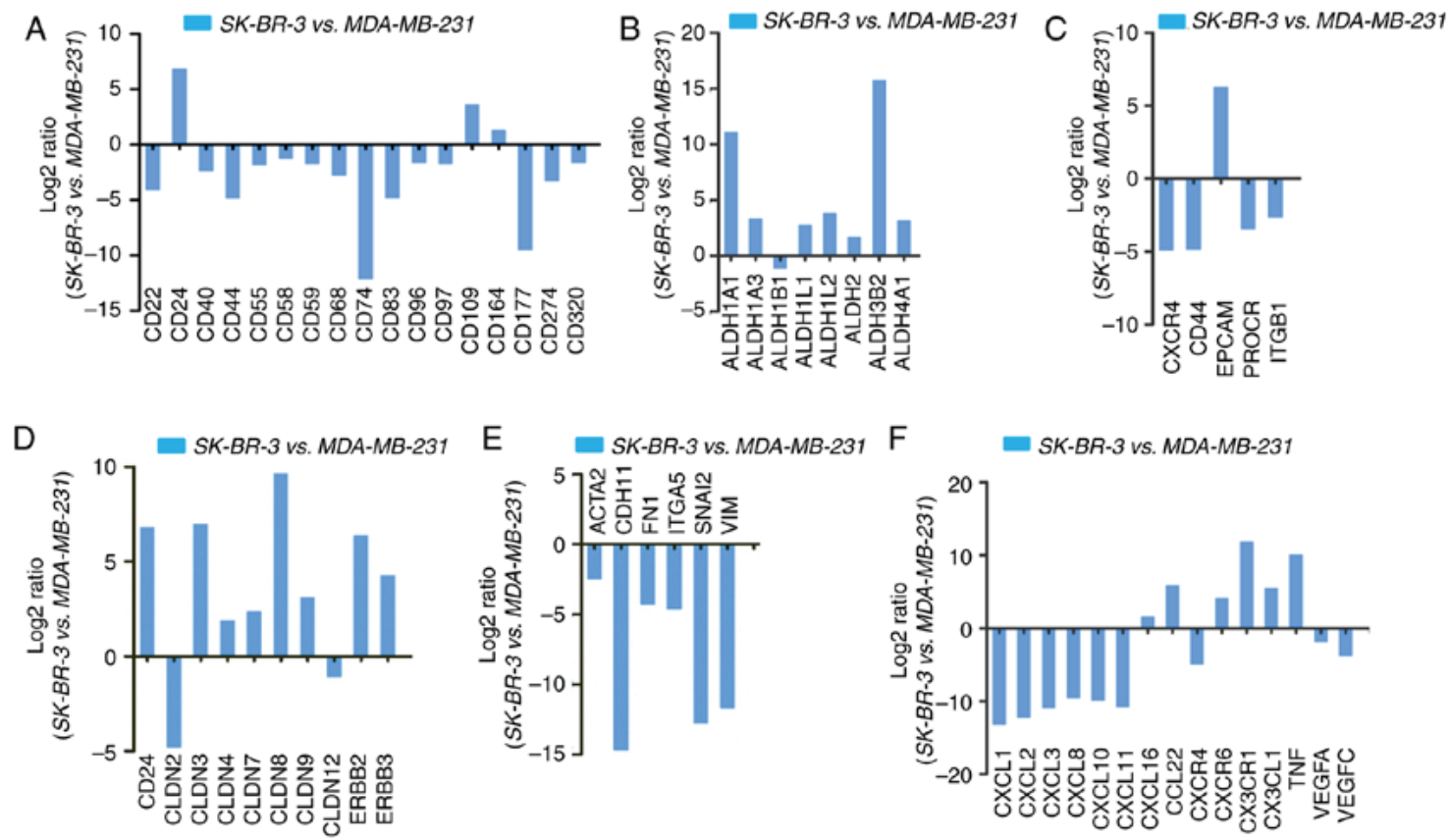

Figure 3. Screening of differentially expressed genes in SKBR-3 vs. MDA-MB-231 cells. The bar chart displays the $\log 2$ expression ratio of differentially expressed genes, and the expression of ALDH1A1, ALDH3B2 and EpCAM was significantly increased in SK-BR-3 vs. MDA-MB-231 cells. (A) Leukocyte markers; (B) ALDH family; (C) CSC markers; (D) epithelial markers; (E) mesenchymal markers; (F) cytokines and receptors in SK-BR-3 vs. MDA-MB-231 cells. ALDH, aldehyde dehydrogenase; CSC, cancer stem cell. 
Table II. Screening of differentially expressed genes related to cancer stem cell markers, EMT and microenvironment of CSCs in SK-BR-3 vs. MDA-MB-231 cells.

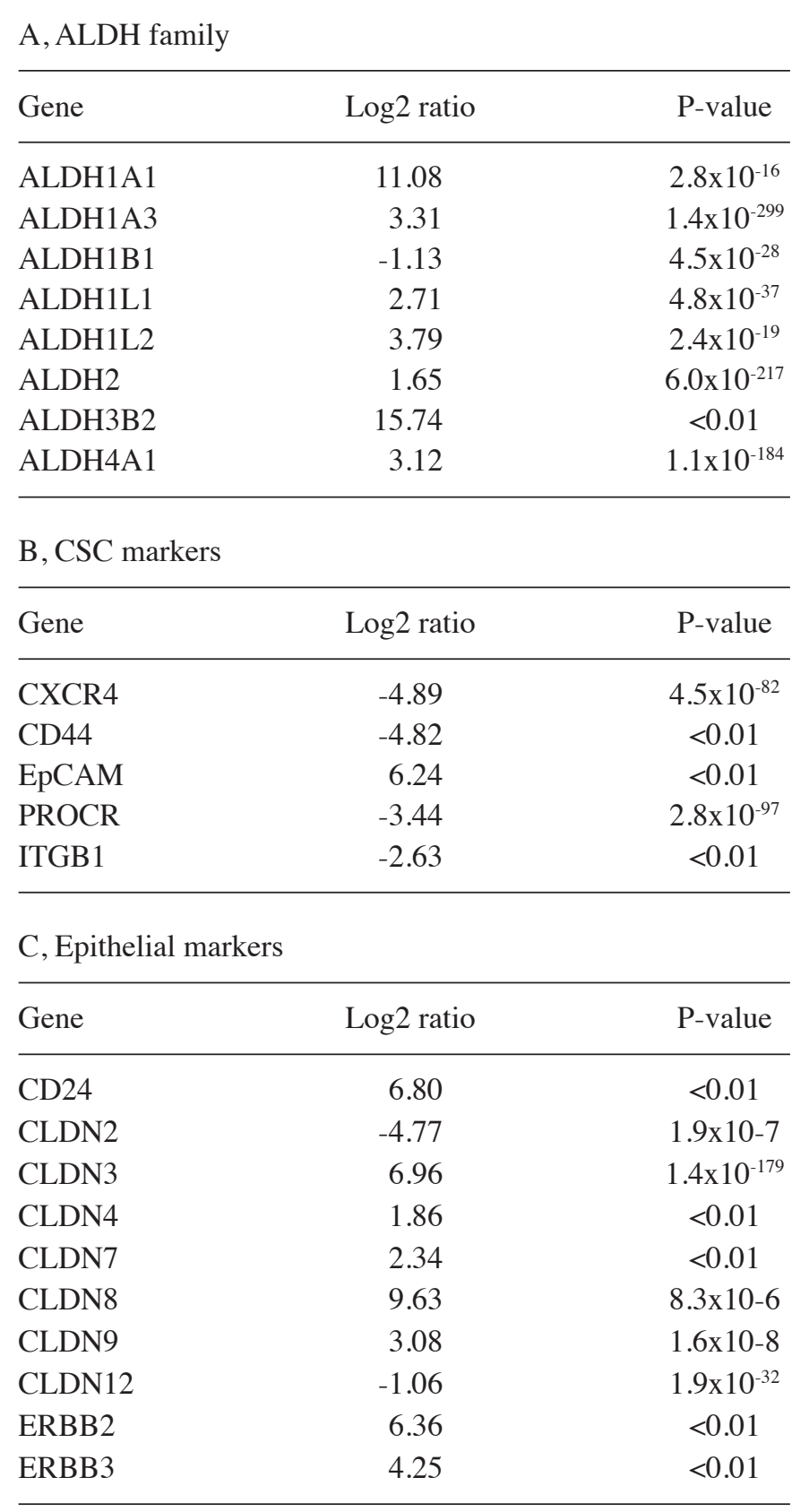

D, Leukocyte markers

\begin{tabular}{lcc}
\hline Gene & Log2 ratio & P-value \\
\hline CD109 & 3.60 & $1.8 \times 10^{-26}$ \\
CD164 & 1.28 & $1.6 \times 10^{-182}$ \\
\hline
\end{tabular}

M, Mesenchymal markers

\begin{tabular}{lcc}
\hline Gene & Log2 ratio & P-value \\
\hline ACTA2 & -2.44 & $9.0 \times 10^{-12}$ \\
CDH11 & -14.69 & $2.7 \times 10^{-295}$ \\
FN1 & -4.25 & $<0.01$ \\
ITGA5 & -4.61 & $<0.01$
\end{tabular}

Table II. Continued.

M, Mesenchymal markers

\begin{tabular}{lcc}
\hline Gene & Log2 ratio & P-value \\
\hline SNAI2 & -12.75 & $1.1 \times 10^{-44}$ \\
VIM & -11.66 & $<0.01$ \\
\hline & & \\
F, Cytokines and receptors & \\
\hline Gene & Log2 ratio & P-value \\
\hline CXCL1 & -13.14 & $3.0 \times 10^{-32}$ \\
CXCL2 & -12.15 & $2.1 \times 10^{-17}$ \\
CXCL3 & -10.85 & $4.3 \times 10^{-7}$ \\
CXCL8 & -2.63 & $5.9 \times 10^{-227}$ \\
CXCL10 & -9.85 & 0.0005 \\
CXCL11 & -10.73 & $6.5 \times 10^{-9}$ \\
CXCL16 & 1.54 & $3.1 \times 10^{-5}$ \\
CCL22 & 5.77 & $1.3 \times 10^{-18}$ \\
CXCR4 & -4.89 & $4.5 \times 10^{-82}$ \\
CXCR6 & 4.04 & 0.0002 \\
CX3CR1 & 11.75 & $2.6 \times 10^{-33}$ \\
CX3CL1 & 5.45 & $1.2 \times 10^{-172}$ \\
TNF & 9.98 & $8.3 \times 10^{-6}$ \\
VEGFA & -1.84 & $<0.01$ \\
VEGFC & -3.72 & $1.2 \times 10^{-128}$ \\
\hline CXH & &
\end{tabular}

ALDH, aldehyde dehydrogenase; CSCs, cancer stem cells.

CD109, CD164 and EpCAM were detected in MCF-10A, SK-BR-3, MCF-7 and MDA-MB-231 cell lines by western blotting. The results revealed that the expression levels of ALDH1A3, CD24, CD164 and EpCAM were higher in SK-BR-3 cells compared with in the other cell lines (Fig. 4C). Ginestier et al (29) observed that ALDH1-expressing cells exhibit the characteristics of CSCs. Among the different subtypes of ALDH1, only ALDH1A3 expression levels (FPKM value) were found to be significantly higher in SK-BR-3 cells in this study (Fig. 4A). ALDH1A3 and ALDH3B2 also belong to the ALDH family, and may have similar functions (Table III). EpCAM-positive liver cancer cells exhibit diverse differentiation ability (30); therefore, EpCAM may be a stem cell marker for HER-2-positive breast cancer. Taken together, these data suggested that ALDH1A3, ALDH3B2 and EpCAM were significantly highly expressed in SK-BR-3 cells, and may be used as stem cell markers for HER-2-positive breast cancer.

ALDH1A3, ALDH3B2 and EpCAM expression status in different subtypes of breast cancer. ALDH1A3, ALDH3B2 and EpCAM protein expression was determined in different subtypes of breast cancer and paracancerous tissues. Among 109 breast cancer cases, 27 (24.8\%) were luminal A, 38 (34.9\%) luminal B, 21 (19.3\%) HER-2-positive and 23 (21.0\%) TNBC (Table IV). The protein expression levels of ALDH1A3, ALDH3B2 and EpCAM were higher in HER-2-positive breast 


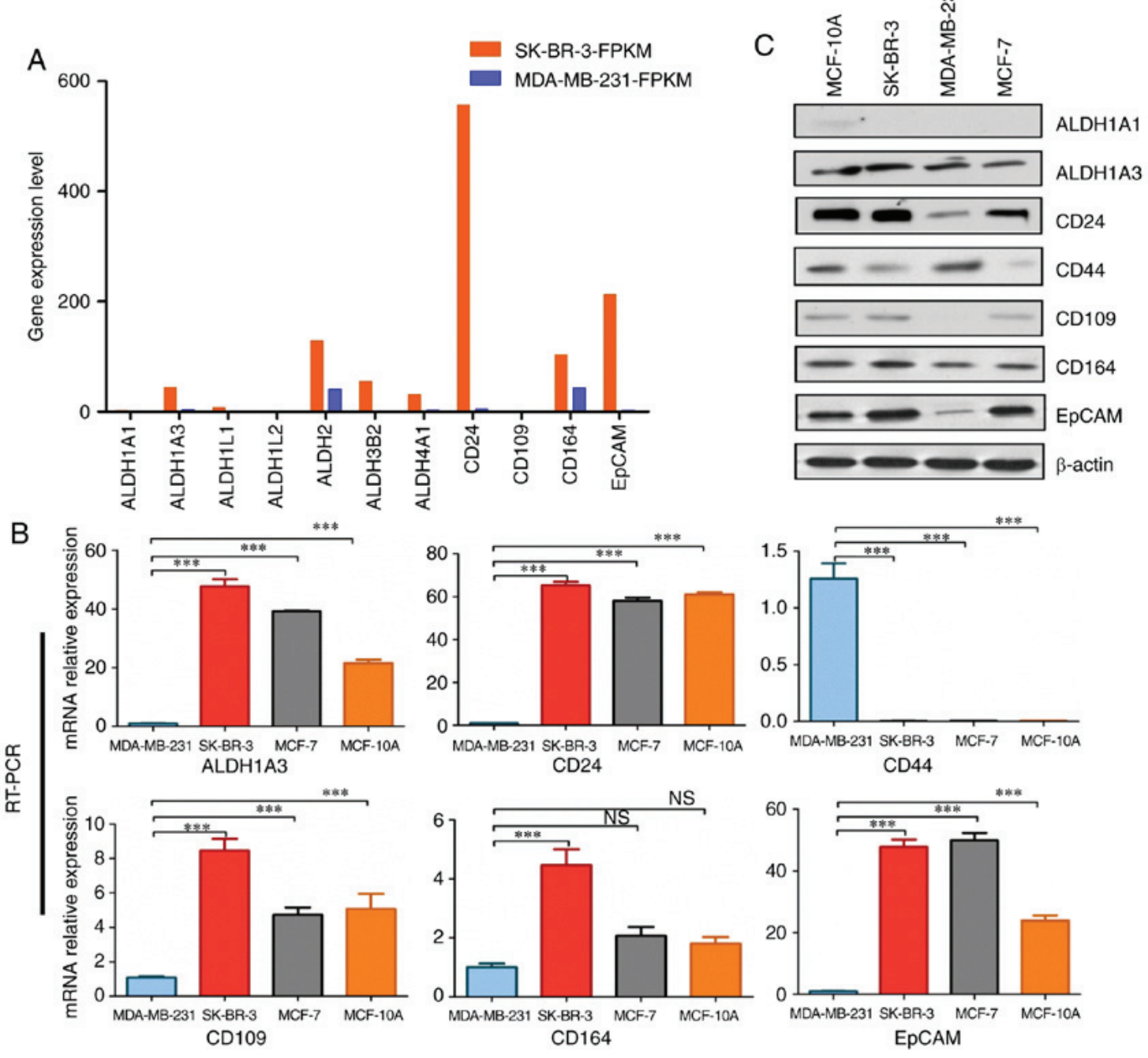

Figure 4. Analysis of upregulated gene expression levels in SK-BR-3 vs. MDA-MB-231 cells. (A) Upregulated gene expression levels in SK-BR-3 vs. MDA-MB-231 cells. The expression levels of ALDH1A3, ALDH3B2, CD24, CD164 and EpCAM were markedly higher in SK-BR-3 cells. FPKM value represents gene expression level. (B) Analysis of upregulated mRNA expression levels in MDA-MB-231, SK-BR-3, MCF-7 and MCF-10A cell lines by RT-qPCR. All cell lines were normalized to the relative expression levels of MDA-MB-231. GADPH was used as an internal reference gene. ${ }^{* * * *} \mathrm{P}<0.001$. Error bars represent standard deviation. RT-qPCR was performed in triplicate. (C) Protein expression levels of ALDH1A1, ALDH1A3, CD24, CD44, CD109, CD164 and EpCAM were detected in MCF-10A, SK-BR-3, MDA-MB-231 and MCF-7 cell lines by western blotting. $\beta$-actin served as a control. ALDH, aldehyde dehydrogenase; EpCAM, epithelial cell adhesion molecule; FPKM, Fragments Per Kilobase of transcript per Million mapped reads; RT-qPCR, reverse transcription-quantitative polymerase chain reaction.

cancer tissues compared with in other subtypes of breast cancer. In addition, among the 109 paracancerous tissue samples, ALDH1A3 was expressed in 9 tissues (8.3\%), ALDH3B2 was expressed in 6 tissues $(5.5 \%)$ and EPCAM was expressed in 37 tissues (33.9\%). Furthermore, ALDH1A3 expression was observed in 16 (76.2\%), ALDH3B2 in 15 (71.4\%) and EpCAM in $18(85.7 \%)$ cases of 21 HER-2-positive breast cancer tissues, whereas ALDH1A3 was expressed in 15 (65.2\%), ALDH3B2 in $13(56.5 \%)$ and EpCAM in $15(65.2 \%)$ of 23 TNBC cases (Fig. 5; Table V). The results of immunohistochemistry for ALDH1A3, ALDH3B2 and EpCAM in different subtypes of breast cancer and paracancerous tissues demonstrated that the expression of ALDH1A3, ALDH3B2 and EpCAM in HER-2-positive breast cancer was higher compared with in other subtypes of breast cancer and paracancerous tissues. Therefore, ALDH1A3, ALDH3B2 and EpCAM may serve as stem cell markers and therapeutic targets for HER-2-positive breast cancer.
KEGG pathway analysis in SK-BR-3 vs. MDA-MB-231 cells. To assess the enrichment in signaling pathways, KEGG was used to analyze the 2,717 upregulated and 3,588 downregulated genes. The top three significantly enriched pathways were 'Pathways in cancer', 'Focal adhesion' and 'MAPK signaling pathway' (Fig. 6; Table VI). The Wnt, Notch, Hedgehog and transforming growth factor (TGF)- $\beta$ signaling pathways are associated with maintaining stemness (31-35). The Wnt signaling pathway is associated with CSC growth, differentiation and apoptosis (36), and $\beta$-catenin serves a key role in cell-cell adhesion and is a key regulatory factor of the Wnt pathway (37). The Wnt inhibitor Wif-1 and the transcriptional repressor of the Wnt pathway Groucho were upregulated in SK-BR-3 cells (Fig. 7). In addition, Dkk, low-density lipoprotein receptor-related protein 5/6 (LRP5/6), $\beta$-catenin and Axin were downregulated in the Wnt pathway in SK-BR-3 cells (Fig. 7). The selected genes (Groucho, Hes1/5, mastermind-like transcriptional coactivator 1 and CSL 
Table III. GO analysis of upregulated genes in SK-BR-3 vs. MDA-MB-231 cells.

A, ALDH1 family

\begin{tabular}{|c|c|c|c|c|}
\hline Gene & $\begin{array}{l}\text { SK-BR-3- } \\
\text { FPKM }\end{array}$ & $\begin{array}{l}\text { MDA-MB- } \\
\text { 231-FPKM }\end{array}$ & Top three GO molecular function & GO biological process \\
\hline ALDH1A1 & 2.17 & 0.001 & $\begin{array}{l}\text { GO:0005083: GTPase regulator } \\
\text { activity; GO:0004030: Aldehyde } \\
\text { dehydrogenase [NAD }(\mathrm{P})+] \text { activity; } \\
\text { GO:000549: Steroid binding }\end{array}$ & $\begin{array}{l}\text { GO:0006067: Ethanol metabolic process; } \\
\text { GO:0044237: Cellular metabolic process }\end{array}$ \\
\hline ALDH1A3 & 43.85 & 4.410 & $\begin{array}{l}\text { GO:0004030: Aldehyde dehydrogenase } \\
\text { [NAD }(\mathrm{P})+] \text { activity; GO:0051287: } \\
\text { NAD binding; GO:0042562: Hormone } \\
\text { binding }\end{array}$ & $\begin{array}{l}\text { GO:0043010: Camera-type eye } \\
\text { development; GO:0006915: Apoptotic } \\
\text { process; GO:0016331: Morphogenesis of } \\
\text { embryonic epithelium; GO:0042573: } \\
\text { retinoic acid metabolic process }\end{array}$ \\
\hline ALDH1L1 & 7.21 & 1.100 & $\begin{array}{l}\text { GO:0016646: oxidoreductase activity, } \\
\text { acting on the CH-NH group of donors, } \\
\text { NAD or NADP as acceptor; } \\
\text { GO:0005488: Binding }\end{array}$ & $\begin{array}{l}\text { GO:0009256: } 10 \text {-formyltetrahydrofolate } \\
\text { metabolic process; GO:0006730: one- } \\
\text { carbon metabolic process }\end{array}$ \\
\hline ALDH1L2 & 1.11 & 0.080 & & \\
\hline ALDH3B2 & 54.74 & 0.001 & $\begin{array}{l}\text { GO:0016620: Oxidoreductase activity, } \\
\text { acting on the aldehyde or oxo group of } \\
\text { donors, NAD or NADP as acceptor }\end{array}$ & $\begin{array}{l}\text { GO:0044237: Cellular metabolic process; } \\
\text { GO:0044281: Small molecule metabolic } \\
\text { process }\end{array}$ \\
\hline ALDH4A1 & 30.71 & $3.54 \mathrm{~A}$ & $\begin{array}{l}\text { GO:0004030: Aldehyde dehydrogenase } \\
\text { [NAD }(\mathrm{P})+] \text { activity; GO:0016646: } \\
\text { Oxidoreductase activity, acting on the } \\
\text { CH-NH group of donors, NAD or } \\
\text { NADP as acceptor }\end{array}$ & GO:0006560: Proline metabolic process \\
\hline
\end{tabular}

B, Leukocyte markers

\begin{tabular}{|c|c|c|c|c|}
\hline Gene & $\begin{array}{l}\text { SK-BR-3- } \\
\text { FPKM }\end{array}$ & $\begin{array}{l}\text { MDA-MB- } \\
\text { 231-FPKM }\end{array}$ & Top three GO function & GO process \\
\hline CD24 & 556.79 & 4.97 & & \\
\hline CD109 & 1.33 & 0.11 & $\begin{array}{l}\text { GO:0004866: endopeptidase inhibitor } \\
\text { activity }\end{array}$ & \\
\hline CD164 & 103.61 & 42.72 & GO:0005488: binding & $\begin{array}{l}\text { GO:0016337: Single organismal cell-cell } \\
\text { adhesion; GO:0008283: Cell population } \\
\text { proliferation; GO: 0023052: Signaling }\end{array}$ \\
\hline
\end{tabular}

C, CSC markers

\begin{tabular}{lcccc}
\hline Gene & $\begin{array}{c}\text { SK-BR-3- } \\
\text { FPKM }\end{array}$ & $\begin{array}{c}\text { MDA-MB- } \\
\text { 231-FPKM }\end{array}$ & Top three GO function & GO process \\
\hline EpCAM & 212.22 & 2.800 &
\end{tabular}

ALDH, aldehyde dehydrogenase; CSC, cancer stem cell.

(a class of DNA binding proteins) of the Notch pathway, which participate in tumor self-renewal and differentiation, were altered in SK-BR-3 cells (Fig. 8). Furthermore, the expression of Smad6/7 in the TGF- $\beta$ pathway was higher in SK-BR-3 cells, whereas the expression levels of Smurf1/2, Smad2/3 and Smad4 were reduced (Fig. 9). Notably, there were several downregulated genes in the Hedgehog signaling pathway, such as the transcription factor $\mathrm{Ci}$, and the Hip, Megalin, 
Table IV. Patient characteristics.

\begin{tabular}{|c|c|}
\hline Parameter & Values \\
\hline \multicolumn{2}{|l|}{ Age, years } \\
\hline Median & 53.6 \\
\hline Range & $35-77$ \\
\hline \multicolumn{2}{|c|}{ Menopausal status, n (\%) } \\
\hline Premenopausal & $41(37.6)$ \\
\hline Postmenopausal & $68(62.4)$ \\
\hline \multicolumn{2}{|l|}{ Tumor size, n (\%) } \\
\hline$\leq 2 \mathrm{~cm}$ & $65(59.6)$ \\
\hline$>2 \mathrm{~cm}$ & $44(40.4)$ \\
\hline \multicolumn{2}{|l|}{ Nodal status, n (\%) } \\
\hline$\leq 3$ & $58(53.2)$ \\
\hline$\geq 4$ & $51(46.8)$ \\
\hline \multicolumn{2}{|c|}{ Tumor histology, n (\%) } \\
\hline Ductal carcinoma & $95(87.2)$ \\
\hline Lobular carcinoma & $3(2.8)$ \\
\hline Other & $11(10.0)$ \\
\hline \multicolumn{2}{|c|}{ Histological grade, $\mathrm{n}(\%)$} \\
\hline $\mathrm{I}$ & $33(30.3)$ \\
\hline II & $20(18.3)$ \\
\hline III & $56(51.4)$ \\
\hline \multicolumn{2}{|l|}{$\mathrm{Ki}-67, \mathrm{n}(\%)$} \\
\hline$<14 \%$ & $34(31.2)$ \\
\hline$\geq 14 \%$ & $75(68.8)$ \\
\hline \multicolumn{2}{|l|}{$\mathrm{ER}, \mathrm{n}(\%)$} \\
\hline Negative & $46(42.2)$ \\
\hline Positive & $63(57.8)$ \\
\hline \multicolumn{2}{|l|}{$\mathrm{PR}, \mathrm{n}(\%)$} \\
\hline Negative & $49(45.0)$ \\
\hline Positive & $60(55.0)$ \\
\hline \multicolumn{2}{|l|}{ HER-2, n (\%) } \\
\hline Negative & $66(60.6)$ \\
\hline Positive & $43(39.4)$ \\
\hline \multicolumn{2}{|l|}{ Subtype, n (\%) } \\
\hline Luminal A & $27(24.8)$ \\
\hline Luminal B & $38(34.9)$ \\
\hline Her-2-positive & $21(19.3)$ \\
\hline Triple-negative & $23(21.0)$ \\
\hline
\end{tabular}

ER, estrogen receptor; HER-2, human epidermal growth receptor-2; $\mathrm{PR}$, progesterone receptor.

Rab23, Fused, protein kinase-A, casein kinase 1, Slimb and Zic2 (Hpe5) genes (Fig. 10). $\beta$-catenin is a key intracellular signaling protein of the Wnt pathway, which triggers the expression of target genes c-Myc and cyclin D1 (37). A high level of $\beta$-catenin expression in tumor cells also indicates a poor prognosis $(37,38)$. Therefore, the expression of $\beta$-catenin was reduced in SK-BR-3 cells compared with in MDA-MB-231 cells, and may serve as a prognostic indicator for breast cancer.
Other gene alterations in stem cell-related signaling pathways require further observation.

Chemokines and receptors in SK-BR-3 vs. MDA-MB-231 cells. The present study detected a statistically significant increase in the expression of several genes (Fig. 3F; Table II). [C-C motif chemokine ligand 22 (CCL22), C-X3-C motif chemokine receptor 1 (CX3CR1) and $\mathrm{C}-\mathrm{X} 3-\mathrm{C}$ motif chemokine ligand 1 (CX3CL1)] in SK-BR-3 cells. Conversely, significantly decreased expression of chemokine subfamily members [C-X-C motif chemokine ligand (CXCL)1, CXCL2, CXCL3, CXCL8, CXCL10 and CXCL11] was detected in SK-BR-3 cells. A previous study indicated that vascular endothelial growth factor (VEGF) may promote tumor growth by autocrine secretion (39). VEGF also stimulates the proliferation and migration of vascular endothelial cells through paracrine secretion and enhances angiogenesis, thereby promoting tumor development and metastasis (39). Among the members of the VEGF family, VEGFA and VEGFC are lymphokine factors that are abundantly expressed in invasive cells, such as melanoma, non-small-cell lung cancer and breast cancer cells, and are considered to be involved in tumor angiogenesis and metastasis $(40,41)$. The present analysis demonstrated that the expression levels of VEGFA and VEGFC were low in SK-BR-3 cells (Fig. 3F; Table II). Further studies are required to elucidate the role of increased expression of certain genes, such as CCL22, CX3CR1 and CX3CL1, in SK-BR-3 cells.

\section{Discussion}

In the present study, the $\mathrm{CD} 44^{+} / \mathrm{CD} 24^{-/ \text {low }}$ ratio was $>90 \%$ in MDA-MB-231 cells; however, there were almost no CD $44^{+} / \mathrm{CD} 24^{-/ \text {low }}$ cells among SK-BR-3 cells. In 2003, Al-Hajj et al (23) demonstrated that CD $44^{+} / \mathrm{CD} 24^{-/ \text {low }}$ cells in breast cancer tissue had tumor-forming ability, and these $\mathrm{CD} 44^{+} / \mathrm{CD} 24^{-/ \text {low }}$ breast cancer cells could not only proliferate indefinitely, but also had the ability of asymmetric differentiation and self-renewal, further proving that $\mathrm{CD} 44^{+} / \mathrm{CD} 24^{-/ \text {low }}$ breast cancer cells exhibit CSC characteristics $(42,43)$. CD $44^{+} / \mathrm{CD} 24^{-/ \text {low }}$ is currently the most commonly used marker for breast CSCs (23). Furthermore, $\mathrm{CD} 44^{+} / \mathrm{CD} 24^{-/ \text {low }}$ cells possess the ability to form microspheres (44); therefore, the microsphere-forming ability of SK-BR-3 cells was weaker than that of MDA-MB-231 cells. In addition, the results demonstrated that both SK-BR-3 and MDA-MB-231 cells exhibit strong migratory and invasive abilities. CSCs are considered to be the key to tumor recurrence and metastasis (45). These results indicated that, although $\mathrm{CD} 44^{+} / \mathrm{CD} 24^{-/ \text {low }}$ breast cancer cells have the characteristics of CSCs, CD $44^{+} / \mathrm{CD} 24^{-/ \text {low }}$ may not be an accurate stem cell marker of SK-BR-3 cells. Therefore, it may be hypothesized that there are other types of CSC markers in SK-BR-3 cells.

Using RNA sequencing and other experiments, it was revealed that the expression levels of CSC markers, such as ALDH1A3, ALDH3B2, CD164 and EpCAM, were markedly upregulated in SK-BR-3 cells and HER-2-positive breast cancer. In a previous study, Ginestier et al (29) reported that ALDH1-positive cells account for $8 \%$ of normal human breast epithelial cells and possess the characteristics of CSCs. A xenograft transplantation experiment in NOD/SCID mice 
Table V. Expression of ALDH1A3, ALDH3B2 and EpCAM in paracancerous tissues and different subtypes of breast cancer.

\begin{tabular}{|c|c|c|c|c|c|c|c|}
\hline \multirow[b]{2}{*}{ Group } & \multirow[b]{2}{*}{$\mathrm{n}$} & \multicolumn{2}{|c|}{ ALDH1A3 } & \multicolumn{2}{|c|}{ ALDH3B2 } & \multicolumn{2}{|c|}{ EpCAM } \\
\hline & & Positive, n (\%) & Negative, $\mathrm{n}(\%)$ & Positive, n (\%) & Negative, $\mathrm{n}(\%)$ & Positive, $\mathrm{n}(\%)$ & Negative, n (\%) \\
\hline Paracancerous tissues & 109 & $9(8.3)$ & $100(91.7)$ & $6(5.5)$ & $103(94.5)$ & 37 (33.9) & $72(66.1)$ \\
\hline HER-2-positive & 21 & $16(76.2)$ & $5(23.8)$ & 15 (71.4) & $6(28.6)$ & $18(85.7)$ & $3(14.3)$ \\
\hline Triple-negative & 23 & $15(65.2)$ & $8(34.8)$ & $13(56.5)$ & $10(43.5)$ & $15(65.2)$ & $8(34.8)$ \\
\hline Luminal A & 27 & $5(18.5)$ & $22(81.5)$ & $4(14.8)$ & $23(85.2)$ & $19(70.4)$ & $8(29.6)$ \\
\hline Luminal B & 38 & $10(26.3)$ & $28(73.7)$ & $13(34.2)$ & $25(65.8)$ & $26(68.4)$ & $12(31.6)$ \\
\hline
\end{tabular}

ALDH, aldehyde dehydrogenase; EpCAM, epithelial cell adhesion molecule; HER-2, human epidermal growth receptor-2.

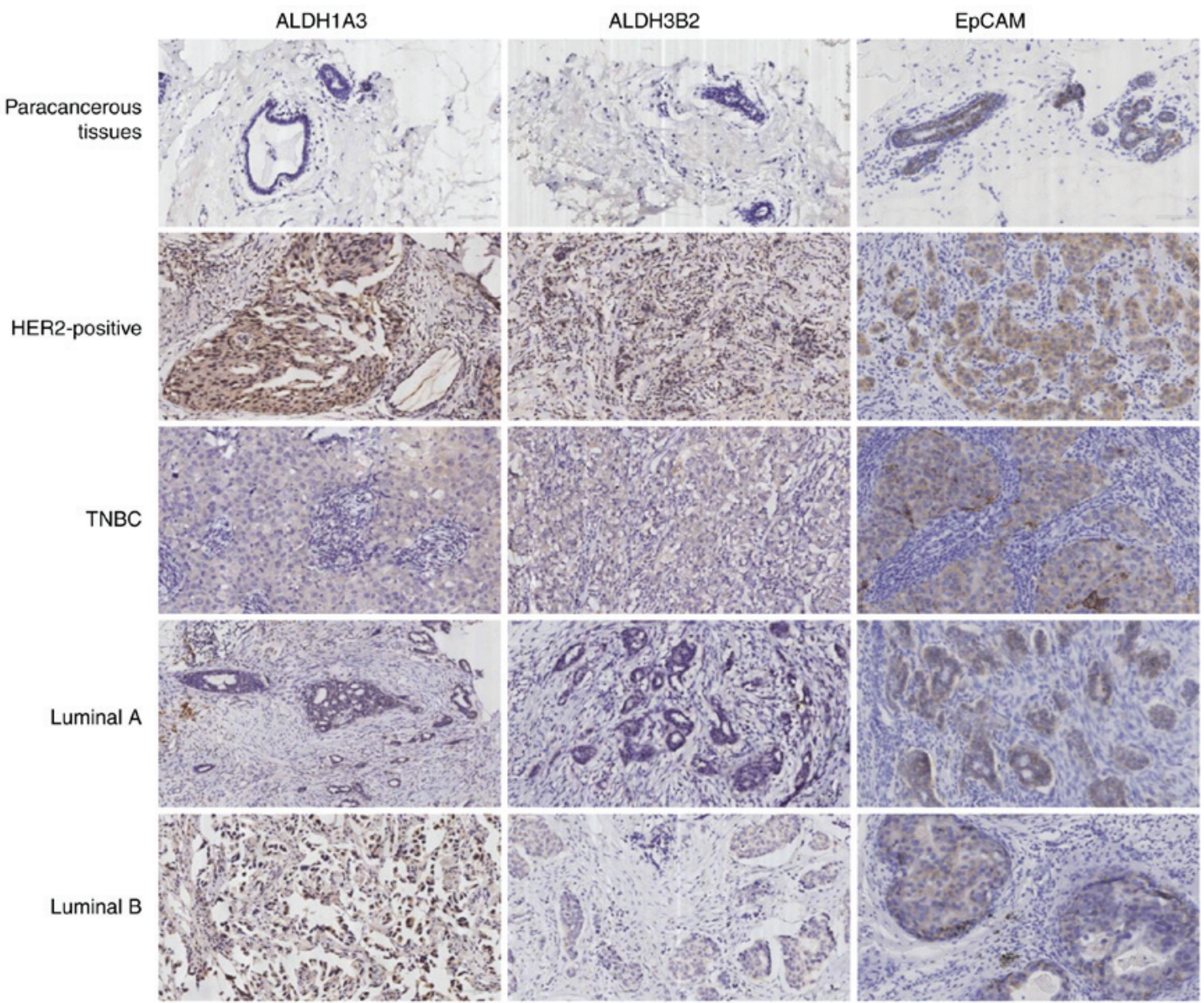

Figure 5. Immunohistochemical expression of ALDH1A3, ALDH3B2 and EpCAM markers in paracancerous tissues and different subtypes of breast cancer (magnification, x200). ALDH, aldehyde dehydrogenase; EpCAM, epithelial cell adhesion molecule; HER2, human epidermal growth factor receptor-2; TNBC, triple-negative breast cancer.

was subsequently performed, and the results demonstrated that $500 \mathrm{ALDH}^{+}{ }^{+}$cells were able to form a tumor, but 50,000 ALDH1 ${ }^{-}$cells failed to form a tumor (29). The ALDH family has 19 enzymes in human cells, which are widely distributed in various tissues and catalyze the oxidation of various aldehydes. ALDH1A3 and ALDH3B2 belong to the ALDH family (46); ALDH1 has been considered a CSC marker in several types of cancer (29); however, only ALDH1A3 gene expression levels (based on FPKM value) were significantly increased in SK-BR-3 cells. ALDH1A3 and ALDH3B2 may have similar functions, and may be used as CSC markers in SK-BR-3 cells, although further investigation is required. EpCAM was first identified in colon cancer, and has been reported to be involved in regulating cell adhesion, proliferation, differentiation, migration and signal transduction (47). Kimura et al (30) observed that EpCAM-positive liver CSCs could form tumors in SCID mice. In this previous study, EpCAM-positive and -negative subgroups of hepatocellular 
Table VI. Pathway enrichment analysis of DEGs in SK-BR-3 vs. MDA-MB-231 cells.

\begin{tabular}{lcc}
\hline Pathway & DEGs with the pathway annotation (n/5138, \%) & P-value \\
\hline Pathways in cancer & $200(3.89)$ & $2.5 \times 10^{-5}$ \\
Focal adhesion & $176(3.43)$ & 0.0003 \\
MAPK signaling pathway & $169(3.25)$ & $4.06 \times 10^{-6}$ \\
HTLV-1 infection & $148(2.88)$ & $2.3 \times 10^{-5}$ \\
Axon guidance & $121(2.36)$ & 0.0001 \\
Cell adhesion molecules (CAMs) & $97(1.89)$ & $2.90 \times 10^{-7}$ \\
Osteoclast differentiation & $91(1.77)$ & $1.34 \times 10^{-5}$ \\
Toxoplasmosis & $79(1.54)$ & $9.9 \times 10^{-5}$ \\
Adhere junction & $72(1.4)$ & 0.0005 \\
NF-KB signaling pathway & $72(1.4)$ & 0.0006 \\
Rheumatoid arthritis & $54(1.05)$ & $2.6 \times 10^{-5}$
\end{tabular}

Pathways with $\mathrm{P} \leq 0.05$ are significantly enriched in DEGs. DEGs, differentially expressed genes.

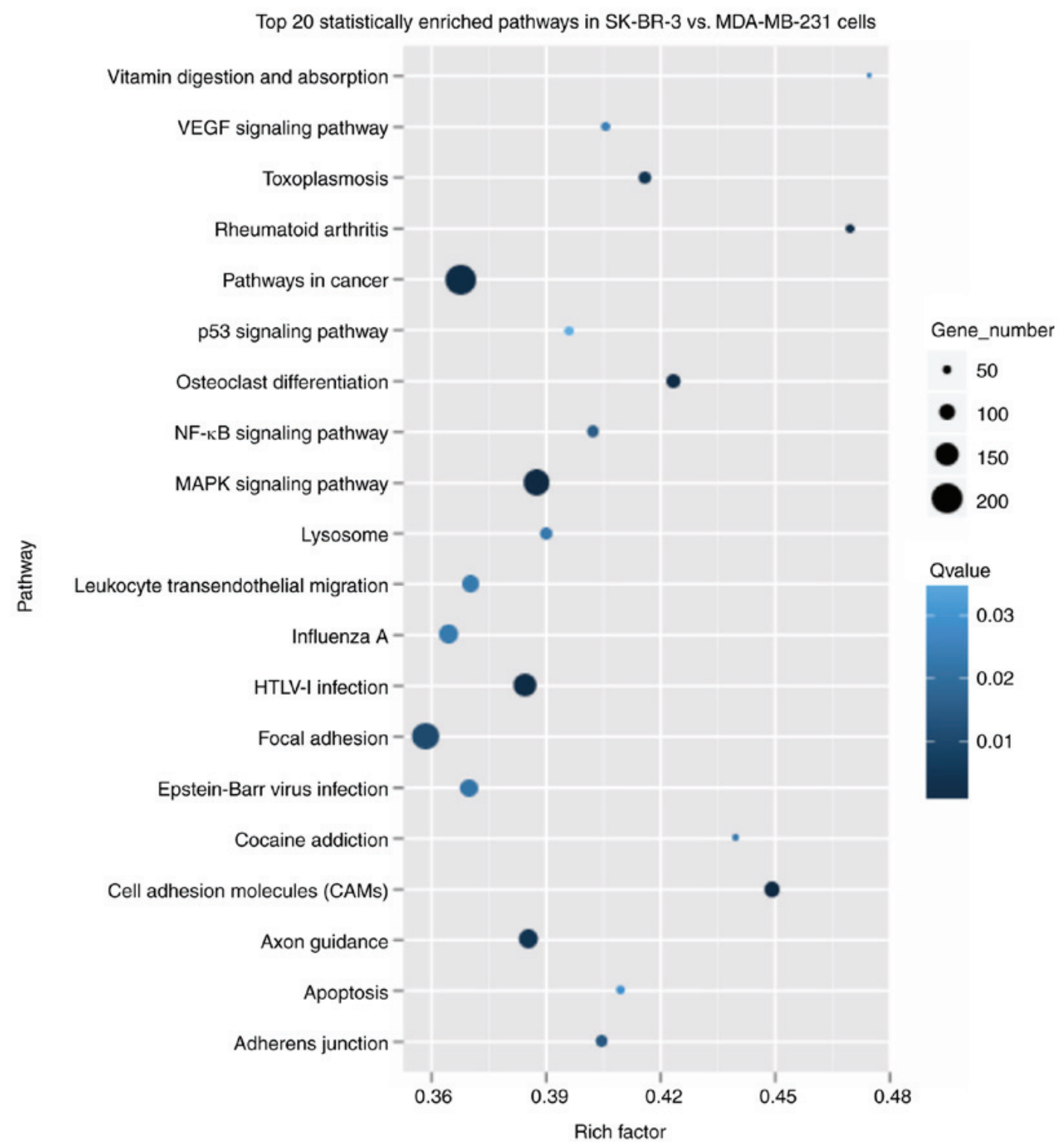

Figure 6. Top 20 statistically enriched pathways in SK-BR-3 vs. MDA-MB-231 cells. Rich factor is the ratio of differentially expressed gene numbers annotated in this pathway term to all gene numbers annotated in this pathway term; a higher value reflects greater intensiveness. Q-value is the corrected P-value ranging between 0 and 1; a lower value reflects greater intensity. KEGG, Kyoto Encyclopedia of Genes and Genomes. 


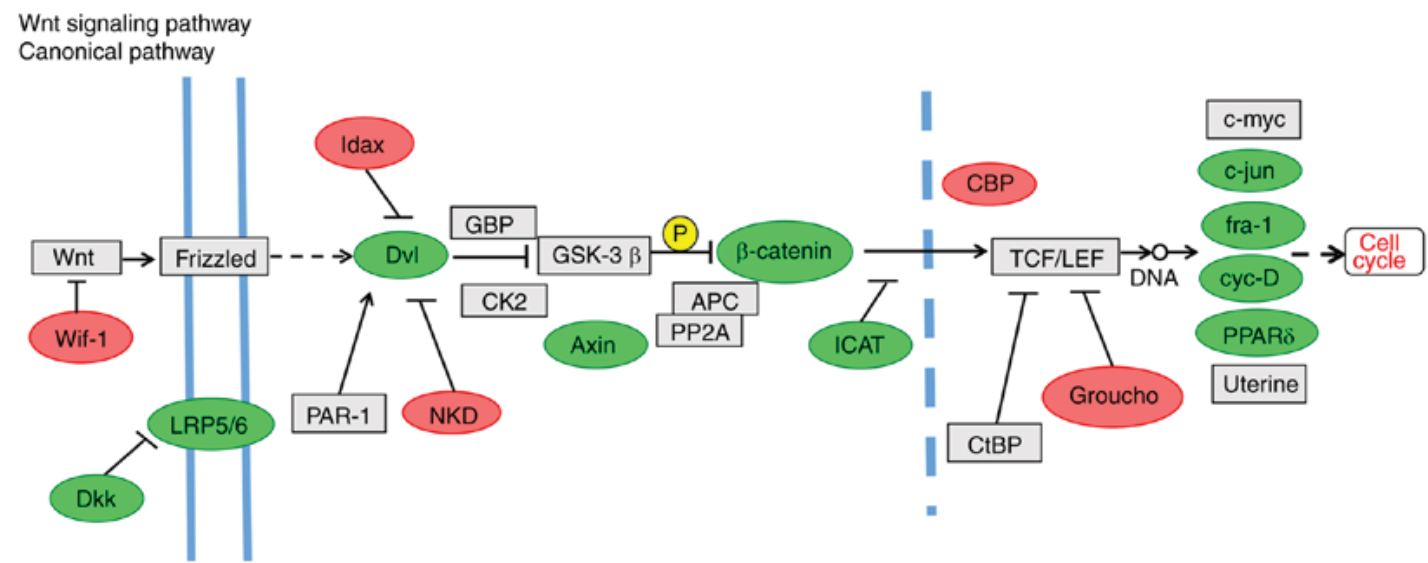

Figure 7. Kyoto Encyclopedia of Genes and Genomes pathway analysis in SK-BR-3 vs. MDA-MB-231 cells. Detailed information of the Wnt signaling pathway. The Wnt inhibitor Wif-1 and transcriptional repressor of the Wnt pathway Groucho were upregulated in SK-BR-3 cells. In addition, Dkk, LRP5/6, $\beta$-catenin and Axin were downregulated in SK-BR-3 cells. In this figure 7, figure 8, figure 9 and figure 10 upregulated genes in SK-BR-3 cells are marked in red, whereas downregulated genes in SK-BR-3 cells are marked in green. Unaltered genes are marked in grey.

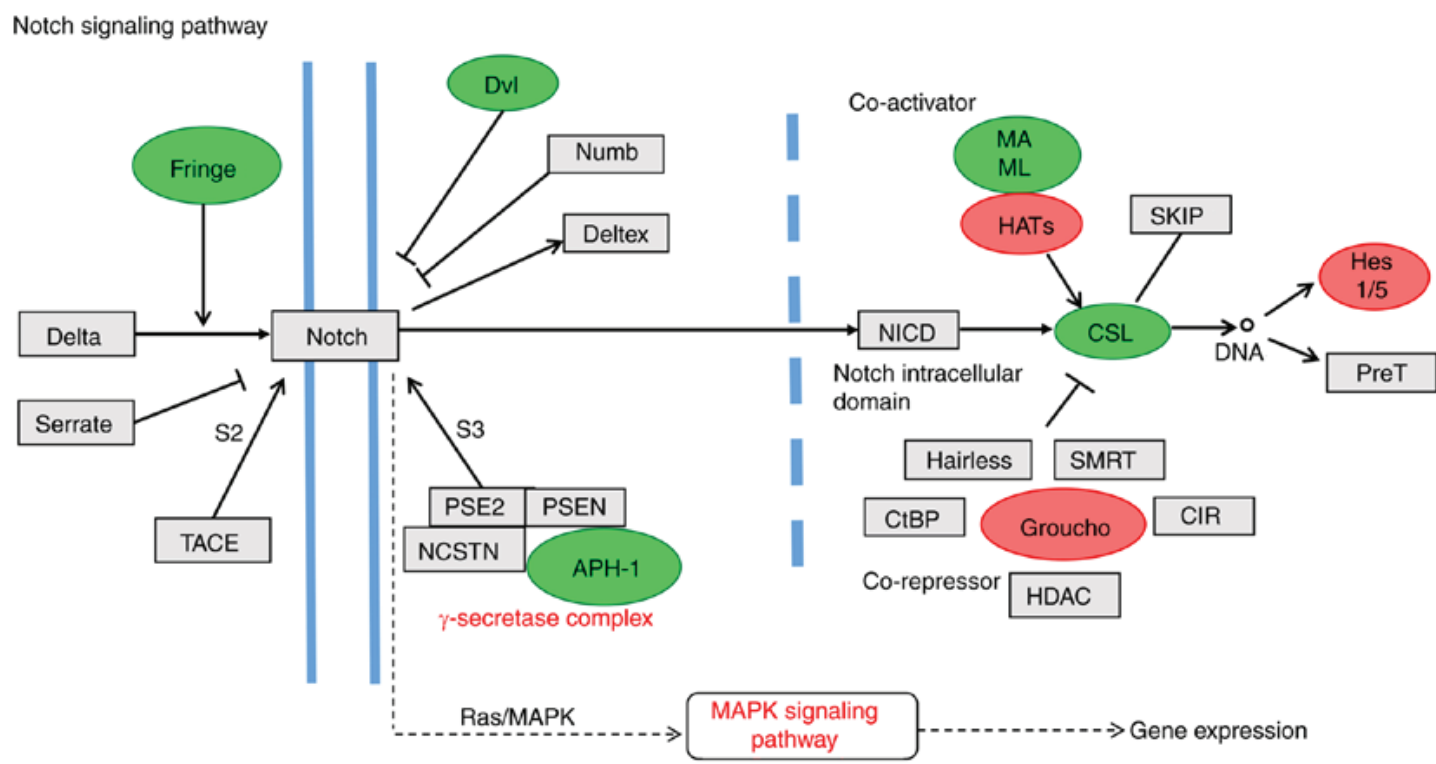

Figure 8. Kyoto Encyclopedia of Genes and Genomes pathway analysis in SK-BR-3 vs. MDA-MB-231 cells. Detailed information of the Notch signaling pathway. Upregulated genes in SK-BR-3 cells are marked in red, whereas downregulated genes in SK-BR-3 cells are marked in green. Unaltered genes are marked in grey.

carcinoma cells were injected into the immune-deficient mice; the results demonstrated that a markedly smaller number of EpCAM-positive cells was sufficient to form a tumor compared with EpCAM-negative cells, indicating that the tumorigenicity of the EpCAM-positive cancer cells was stronger. This study also demonstrated that EpCAM-positive cancer cells could differentiate into EpCAM-positive and-negative cells, whereas EpCAM-negative cancer cells could only differentiate into EpCAM-negative cells, indicating that only EpCAM-positive cancer cells exhibit diversity in their differentiation ability (30). Therefore, EpCAM is likely to represent a CSC marker for SK-BR-3 cells. CD164 functions include mediating or regulating the adhesion of hematopoietic progenitor cells, and their growth and/or differentiation $(48,49)$. Previous studies have reported that CD164 not only regulates the growth and differentiation of hematopoietic progenitor cells, but also promotes the growth and invasion of malignant tumors $(50,51)$. CD164 is also considered a potential promoter for regulating tumor growth, and a diagnostic marker for acute lymphoblastic leukemia and allergy (52-54). The potential relationship between CD164 and CSCs remains unclear. Previous studies (48-54) have demonstrated that CD164 may be used as a potential therapeutic target for HER-2-positive breast cancer.

EMT gene expression was examined in SK-BR-3 cells in this study. Certain epithelial marker genes, including CD24, CLDN3, CLDN8 and ERBB2, were upregulated, whereas mesenchymal markers, such as ACTA2, CDH11, FN1, ITGA5, SNAI2 and VIM, were markedly downregulated. EMT can result in acquisition of the behavior of stromal cells, which is the key to early invasion and metastasis of breast cancer $(55,56)$, and is a sign of poor prognosis of breast cancer (57). The EMT ability of SK-BR-3 cells is weak compared with that 


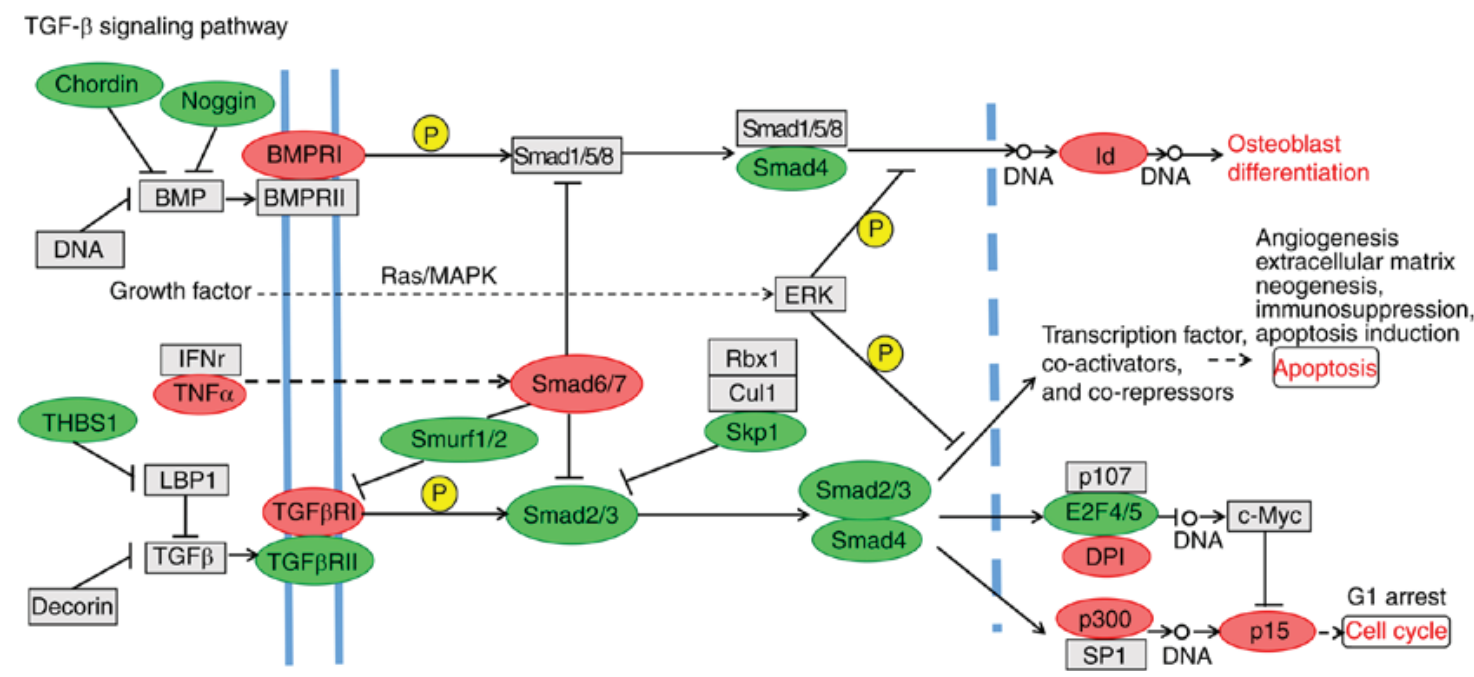

Fjgure 9. Kyoto Encyclopedia of Genes and Genomes pathway analysis in SK-BR-3 vs. MDA-MB-231 cells. Detailed information of the TGF- $\beta$ signaling pathway.

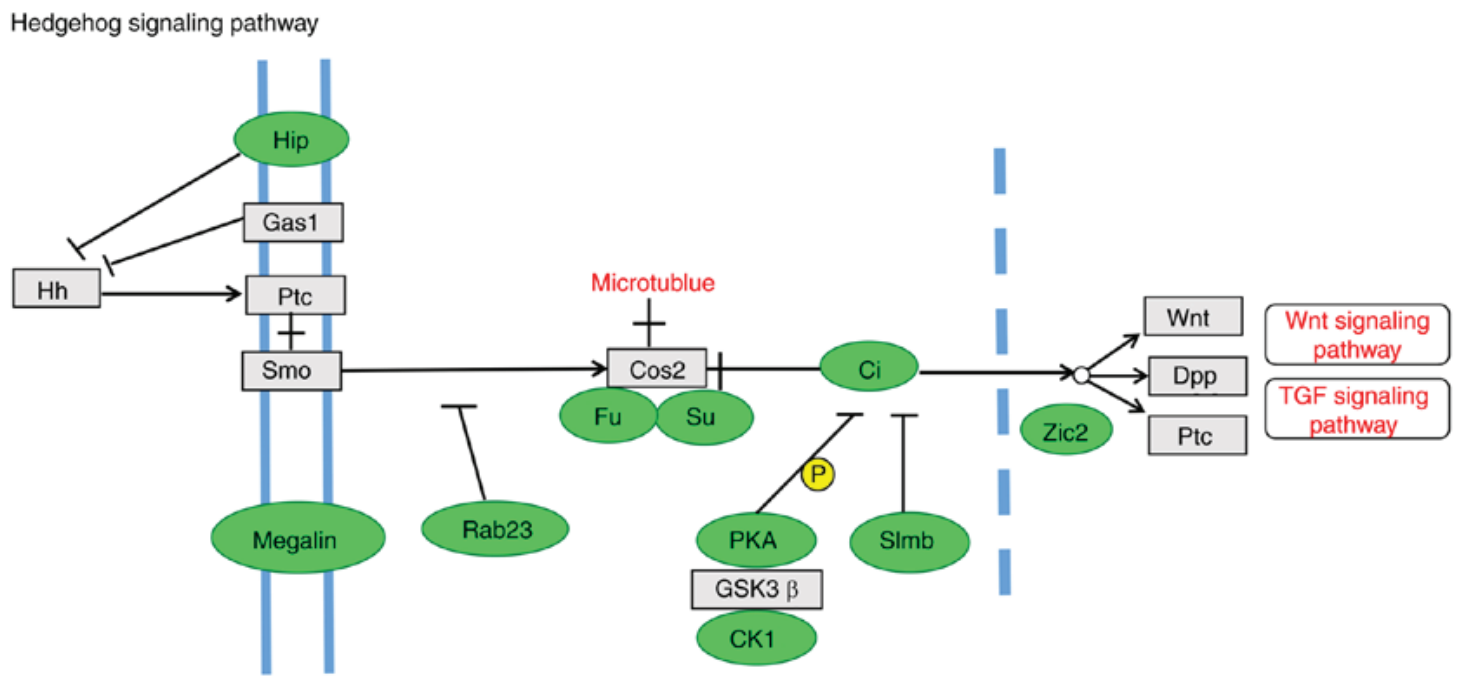

Figure 10. Kyoto Encyclopedia of Genes and Genomes pathway analysis in SK-BR-3 vs. MDA-MB-231 cells. Detailed information of the Hedgehog signaling pathway.

of MDA-MB-231 cells, thus epithelial marker genes were upregulated and mesenchymal genes were downregulated.

Under physiological conditions, cell proliferation, apoptosis, differentiation and regeneration are strictly regulated by signaling transduction pathways. Once a component of the signaling transduction pathway is mutated or otherwise altered, the cells may display abnormal differentiation and unrestricted growth, eventually forming tumors (58). $\beta$-catenin is a key intracellular signaling protein of the Wnt pathway, which triggers the expression of target genes c-Myc and cyclin D1 (37). A high level of $\beta$-catenin expression in tumor cells also indicates a poor prognosis $(37,38)$. In agreement with these data, the results demonstrated that the expression of $\beta$-catenin was lower in SK-BR-3 cells compared with in MDA-MB-231 cells. Therefore, $\beta$-catenin may be a prognostic indicator for patients with breast cancer, as well as a novel target for TNBC treatment in the future. The MAPK signaling pathway was highly active in SK-BR-3 cells; therefore, investigating the molecular mechanisms involved in the MAPK signaling pathway may provide a new method for the treatment of HER-2-positive breast cancer.

It has been reported that tumor cells and stromal cells may express chemokines and receptors, which can mediate tumor progression and metastasis. Chemokines and their receptors may enhance tumor growth by regulating the tumor inflammatory response, increasing angiogenesis, and inhibiting the anti-tumor immune response to promote tumor development and progression $(59,60)$. The expression of chemokines and receptors, CCL22, CX3CR1 and CX3CL1, were significantly increased in SK-BR-3 cells; however, the roles of these genes in SK-BR-3 cells require further elucidation.

In conclusion, the results of the present study demonstrated that SK-BR-3 cells had almost no CD $44^{+} / \mathrm{CD} 24^{-/ \text {low }}$ expression, and that ALDH1A3, ALDH3B2 and EpCAM may represent CSC markers in SK-BR-3 cells. CD164 may be used as a potential therapeutic target for HER-2-positive breast cancer. 
In addition, $\beta$-catenin of the Wnt signaling pathway may be used as a prognostic indicator for breast cancer. Taken together, these data indicated a novel prognostic indicator, therapeutic targets and a novel approach to the management of HER-2-positive breast cancer.

\section{Acknowledgements}

Not applicable.

\section{Funding}

This work was supported by grants from the National Natural Science Foundation of China (grant no. 81272898).

\section{Availability of data and materials}

The datasets used and/or analyzed during the current study are available from the corresponding author on reasonable request.

\section{Authors' contributions}

SZG and XHZ conceived and designed the study. LF and GA contributed to design and perform the experiments. SHK collected breast cancer and paracancerous tissue samples, and patient data. LF and SHK performed the bioinformatics analysis and statistical analyses. LF and SHK drafted the manuscript. LF and GYW revised the manuscript. All the authors have read and approved the final version of this manuscript.

\section{Ethical approval and consent to participate}

Written informed consent was obtained from the patients, and ethical approval was obtained from the Ethics Committee of The First Affiliated Hospital of Xi'an Jiaotong University (approval no. XJTU1AF2019LSK-2019-029).

\section{Patient consent for publication}

Not applicable.

\section{Competing interests}

The authors declare that they have no competing interests.

\section{References}

1. Ferlay J, Soerjomataram I, Dikshit R, Eser S, Mathers C Rebelo M, Parkin DM, Forman D and Bray F: Cancer incidence and mortality worldwide: Sources, methods and major patterns in GLOBOCAN 2012. Int J Cancer 136: E359-E386, 2015.

2. Ellsworth RE, Blackburn HL, Shriver CD, Soon-Shiong P and Ellsworth DL: Molecular heterogeneity in breast cancer: State of the science and implications for patient care. Semin Cell Dev Biol 64: 65-72, 2017

3. Perou CM, Sørlie T, Eisen MB, van de Rijn M, Jeffrey SS, Rees CA, Pollack JR, Ross DT, Johnsen H, Akslen LA, et al: Molecular portraits of human breast tumours. Nature 406 747-752, 2000

4. Slamon DJ, Clark GM, Wong SG, Levin WJ, Ullrich A and McGuire WL: Human breast cancer: Correlation of relapse and survival with amplification of the HER-2/neu oncogene. Science 235: 177-182, 1987.
5. Slamon DJ, Godolphin W, Jones LA, Holt JA, Wong SG, Keith DE, Levin WJ, Stuart SG, Udove J, Ullrich A, et al: Studies of the HER-2/neu proto-oncogene in human breast and ovarian cancer. Science 244: 707-712, 1989.

6. Vogel CL, Cobleigh MA, Tripathy D, Gutheil JC, Harris LN, Fehrenbacher L, Slamon DJ, Murphy M, Novotny WF, Burchmore M, et al: Efficacy and safety of trastuzumab as a single agent in first-line treatment of HER2-overexpressing metastatic breast cancer. J Clin Oncol 20: 719-726, 2002.

7. Baselga J, Carbonell X, Castañeda-Soto NJ, Clemens M, Green M, Harvey V, Morales S, Barton C and Ghahramani P: Phase II study of efficacy, safety, and pharmacokinetics of trastuzumab monotherapy administered on a 3-weekly schedule. J Clin Oncol 23: 2162-2171, 2005.

8. Marty M, Cognetti F, Maraninchi D, Snyder R, Mauriac L, Tubiana-Hulin M, Chan S, Grimes D, Antón A, Lluch A, et al: Randomized phase II trial of the efficacy and safety of trastuzumab combined with docetaxel in patients with human epidermal growth factor receptor 2-positive metastatic breast cancer administered as first-line treatment: The M77001 study group. J Clin Oncol 23: 4265-4274, 2005.

9. Slamon DJ, Leyland-Jones B, Shak S, Fuchs H, Paton V, Bajamonde A, Fleming T, Eiermann W, Wolter J, Pegram M, et al: Use of chemotherapy plus a monoclonal antibody against HER2 for metastatic breast cancer that overexpresses HER2. N Engl J Med 344: 783-792, 2001.

10. Sun Z, Shi Y, Shen Y, Cao L, Zhang W and Guan X: Analysis of different HER-2 mutations in breast cancer progression and drug resistance. J Cell Mol Med 19: 2691-2701, 2015.

11. Pinto AE, André S, Pereira T, Nóbrega S and Soares J: C-erbB-2 oncoprotein overexpression identifies a subgroup of estrogen receptor positive $(\mathrm{ER}+)$ breast cancer patients with poor prognosis. Ann Oncol 12: 525-533, 2001.

12. Bauer KR, Brown M, Cress RD, Parise CA and Caggiano V: Descriptive analysis of estrogen receptor (ER)-negative, progesterone receptor (PR)-negative, and HER2-negative invasive breast cancer, the so-called triple-negative phenotype: A population-based study from the California cancer Registry. Cancer 109: 1721-1728, 2007.

13. Dawood S, Broglio K, Kau SW, Green MC, Giordano SH, Meric-Bernstam F, Buchholz TA, Albarracin C, Yang WT, Hennessy BT, et al: Triple receptor-negative breast cancer: The effect of race on response to primary systemic treatment and survival outcomes. J Clin Oncol 27: 220-226, 2009.

14. Dent R, Trudeau M, Pritchard KI, Hanna WM, Kahn HK, Sawka CA, Lickley LA, Rawlinson E, Sun P and Narod SA: Triple-negative breast cancer: Clinical features and patterns of recurrence. Clin Cancer Res 13: 4429-4434, 2007.

15. Wang Z, Gerstein M and Snyder M: RNA-seq: A revolutionary tool for transcriptomics. Nat Rev Genet 10: 57-63, 2009.

16. Liu T, Yu N, Ding F, Wang S, Li S, Zhang X, Sun X, Chen Y and Liu P: Verifying the markers of ovarian cancer using RNA-seq data. Mol Med Rep 12: 1125-1130, 2015.

17. Li B and Dewey CN: RSEM: Accurate transcript quantification from RNA-Seq data with or without a reference genome. BMC Bioinformatics 12: 323, 2011.

18. Li H and Durbin R: Fast and accurate short read alignment with Burrows-Wheeler transform. Bioinformatics 25: 1754-1760, 2009.

19. Audic S and Claverie JM: The significance of digital gene expression profiles. Genome Res 7: 986-995, 1997.

20. Beissbarth T and Speed TP: GOstat: Find statistically over-represented Gene Ontologies within a group of genes. Bioinformatics 20: 1464-1465, 2004.

21. Mao X, Cai T, Olyarchuk JG and Wei L: Automated genome annotation and pathway identification using the KEGG orthology (KO) as a controlled vocabulary. Bioinformatics 21: 3787-3793, 2005.

22. Livak KJ and Schmittgen TD: Analysis of relative gene expression data using real-time quantitative PCR and the 2(-Delta Delta C(T)) method. Methods 25: 402-408, 2001.

23. Al-Hajj M, Wicha MS, Benito-Hernandez A, Morrison SJ and Clarke MF: Prospective identification of tumorigenic breast cancer cells. Proc Natl Acad Sci USA 100: 3983-3988, 2003.

24. Li W, Ma H, Zhang J, Zhu L, Wang C and Yang Y: Unraveling the roles of CD44/CD24 and ALDH1 as cancer stem cell markers in tumorigenesis and metastasis. Sci Rep 7: 13856, 2017.

25. Shao J, Fan W, Ma B and Wu Y: Breast cancer stem cells expressing different stem cell markers exhibit distinct biological characteristics. Mol Med Rep 14: 4991-4998, 2016. 
26. Yin $\mathrm{H}$ and Glass $\mathrm{J}$ : The phenotypic radiation resistance of CD44+/CD24(-or low) breast cancer cells is mediated through the enhanced activation of ATM signaling. PLoS One 6: e24080, 2011.

27. Zhang J, Kinoh H, Hespel L, Liu X, Quader S, Martin J, Chida T, Cabral $\mathrm{H}$ and Kataoka K: Effective treatment of drug resistant recurrent breast tumors harboring cancer stem-like cells by staurosporine/epirubicin co-loaded polymeric micelles. J Control Release 264: 127-135, 2017.

28. Puchinskaya MV: Cancer stem cell markers and their prognostic value. Arkh Patol 78: 47-54, 2016 (In Russian).

29. Ginestier C, Hur MH, Charafe-Jauffret E, Monville F, Dutcher J, Brown M, Jacquemier J, Viens P, Kleer CG, Liu S, et al: ALDH1 is a marker of normal and malignant human mammary stem cells and a predictor of poor clinical outcome. Cell Stem Cell 1: $555-567,2007$.

30. Kimura O, Takahashi T, Ishii N, Inoue Y, Ueno Y, Kogure T, Fukushima K, Shiina M, Yamagiwa Y, Kondo Y, et al: Characterization of the epithelial cell adhesion molecule $($ EpCAM $)+$ cell population in hepatocellular carcinoma cell lines. Cancer Sci 101: 2145-2155, 2010.

31. Fodde R and Brablet T: Wnt/beta-catenin signaling in cancer stemness and malignant behavior. Curr Opin Cell Biol 19: $150-158,2007$.

32. Androutsellis-Theotokis A, Leker RR, Soldner F, Hoeppner DJ, Ravin R, Poser SW, Rueger MA, Bae SK, Kittappa R and McKay RD: Notch signalling regulates stem cell numbers in vitro and in vivo. Nature 442: 823-826, 2006.

33. Valenti G, Quinn HM, Heynen GJJE, Lan L, Holland JD, Vogel R, Wulf-Goldenberg A and Birchmeier W: Cancer stem cells regulate cancer-associated fibroblasts via activation of Hedgehog signaling in mammary gland tumors. Cancer Res 77: 2134-2147, 2017

34. Daynac M, Tirou L, Faure H, Mouthon MA, Gauthier LR, Hahn H, Boussin FD and Ruat M: Hedgehog controls quiescence and activation of neural stem cells in the adult ventricular-subventricular zone. Stem Cell Reports 7: 735-748, 2016.

35. Sakaki-Yumoto M, Katsuno Y and Derynck R: TGF- $\beta$ family signaling in stem cells. Biochim Biophys Acta 1830: 2280-2296, 2013.

36. Zhang J, Lai W, Li Q, Yu Y, Jin J, Guo W, Zhou X, Liu X and Wang Y: A novel oncolytic adenovirus targeting Wnt signaling effectively inhibits cancer-stem like cell growth via metastasis, apoptosis and autophagy in HCC models. Biochem Biophys Res Commun 491: 469-477, 2017.

37. Khramtsov AI, Khramtsova GF, Tretiakova M, Huo D, Olopade OI and Goss KH: Wnt/beta-catenin pathway activation is enriched in basal-like breast cancers and predicts poor outcome. Am J Pathol 176: 2911-2920, 2010.

38. Li T, Zhang L and Huo X: Inhibitory effects of aesculetin on the proliferation of colon cancer cells by the $\mathrm{Wnt} / \beta$-catenin signaling pathway. Oncol Lett 15: 7118-7122, 2018.

39. Medeiros PJ and Jackson DN: Neuropeptide Y Y5-receptor activation on breast cancer cells acts as a paracrine system that stimulates VEGF expression and secretion to promote angiogenesis. Peptides 48: 106-113, 2013.

40. Zhang Y, Meng X, Zeng H, Guan Y, Zhang Q, Guo S, Liu X and Guo Q: Serum vascular endothelial growth factor-C levels: A possible diagnostic marker for lymph node metastasis in patients with primary non-small cell lung cancer. Oncol Lett 6: 545-549, 2013.

41. Saharinen P, Eklund L, Pulkki K, Bono P and Alitalo K: VEGF and angiopoietin signaling in tumor angiogenesis and metastasis. Trends Mol Med 17: 347-362, 2011.

42. Clarke MF, Dick JE, Dirks PB, Eaves CJ, Jamieson CH, Jones DL, Visvader J, Weissman IL and Wahl GM: Cancer stem cells-perspectives on current status and future directions: AACR Workshop on cancer stem cells. Cancer Res 66: 9339-9344, 2006.
43. Okamoto OK and Perez JF: Targeting cancer stem cells with monoclonal antibodies: A new perspective in cancer therapy and diagnosis. Expert Rev Mol Diagn 8: 387-393, 2008.

44. Phillips TM, McBride WH and Pajonk F: The response of CD24(-/low)/CD44+ breast cancer-initiating cells to radiation. J Natl Cancer Inst 98: 1777-1785, 2006.

45. Sottoriva A, Verhoeff JJ, Borovski T, McWeeney SK, Naumov L, Medema JP, Sloot PM and Vermeulen L: Cancer stem cell tumor model reveals invasive morphology and increased phenotypical heterogeneity. Cancer Res 70: 46-56, 2010.

46. Marcato P, Dean CA, Giacomantonio CA and Lee PW: Aldehyde dehydrogenase: Its role as a cancer stem cell marker comes down to the specific isoform. Cell Cycle 10: 1378-1384, 2011.

47. Yamashita T, Ji J, Budhu A, Forgues M, Yang W, Wang HY, Jia H, Ye Q, Qin LX, Wauthier E, et al: EpCAM-positive hepatocellular carcinoma cells are tumor-initiating cells with stem/progenitor cell features. Gastroenterology 136: 1012-1024, 2009.

48. Watt SM and Chan JY: CD164-a novel sialomucin on CD34+ cells. Leuk Lymphoma 37: 1-25, 2000.

49. Lee YN, Kang JS and Krauss RS: Identification of a role for the sialomucin CD164 in myogenic differentiation by signal sequence trapping in yeast. Mol Cell Biol 21: 7696-7706, 2001.

50. Lin J, Xu K, Wei J, Heimberger AB, Roth JA and Ji L: MicroRNA-124 suppresses tumor cell proliferation and invasion by targeting CD164 signaling pathway in non-small cell lung cancer. J Gene Ther 2: 6, 2016.

51. Tang J, Zhang L, She X, Zhou G, Yu F, Xiang J and Li G: Inhibiting CD164 expression in colon cancer cell line HCT116 leads to reduced cancer cell proliferation, mobility, and metastasis in vitro and in vivo. Cancer Invest 30: 380-389, 2012.

52. Wong PF and Abubakar S: Comparative transcriptional study of the effects of high intracellular zinc on prostate carcinoma cells. Oncol Rep 23: 1501-1516, 2010.

53. Coustan-Smith E, Song G, Clark C, Key L, Liu P, Mehrpooya M, Stow P, Su X, Shurtleff S, Pui CH, et al: New markers for minimal residual disease detection in acute lymphoblastic leukemia. Blood 117: 6267-6276, 2011.

54. Chirumbolo S: CD164 and other recently discovered activation markers as promising tools for allergy diagnosis: What's new? Clin Exp Med 11: 255-257, 2011

55. Arendt LM, Rudnick JA, Keller PJ and Kuperwasser C: Stroma in breast development and disease. Semin Cell Dev Biol 21: $11-18,2010$

56. Thiery JP and Sleeman JP: Complex networks orchestrate epithelial-mesenchymal transitions. Nat Rev Mol Cell Biol 7: 131-142, 2006.

57. He ZY, Wu SG, Peng F, Zhang Q, Luo Y, Chen M and Bao Y: Up-regulation of RFC3 promtes triple negative breast cancer metastasis and is associated with poor prognosis via EMT. Transl Oncol: 10: 1-9, 2017.

58. Ajani JA, Song S, Hochster HS and Steinberg IB: Cancer stem cells: The promise and the potential. Semin Oncol 42 (Suppl 1): S3-S17, 2015

59. Germano G, Allavena P and Mantovani A: Cytokines as a key component of cancer-related inflammation. Cytokine 43: 374-379, 2008.

60. Nagarsheth N, Wicha MS and Zou W: Chemokines in the cancer microenvironment and their relevance in cancer immunotherapy. Nat Rev Immunol 17: 559-572, 2017.

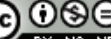

This work is licensed under a Creative Commons Attribution-NonCommercial-NoDerivatives 4.0 International (CC BY-NC-ND 4.0) License. 